\title{
CHEMICALLY ASSISTED IN SITU RECOVERY OF OL SHALE
}

DE-AC22-89BC14479

The Department of Chemical Engineering

The University of Colorado at Boulder

Boulder, Colorado.

Contract Date: September 5, 1989.

Government Award: $\$ 168,013$.

Principle Investigator: W. Fred Ramirez.

Project Manager: Ernie Zuech.

Reporting Period: Termination Report.

Objectives: The objective of this work was to investigate, in the laboratory, the parameters associated with a chemically assisted in situ recovery procedure, using hydrogen chloride $(\mathrm{HCl})$, carbon dioxide $\left(\mathrm{CO}_{2}\right)$, and steam $\left(\mathrm{H}_{2} \mathrm{O}\right)$, to obtain data useful to develop a nrocess more economic than existing processes and to report all findings.
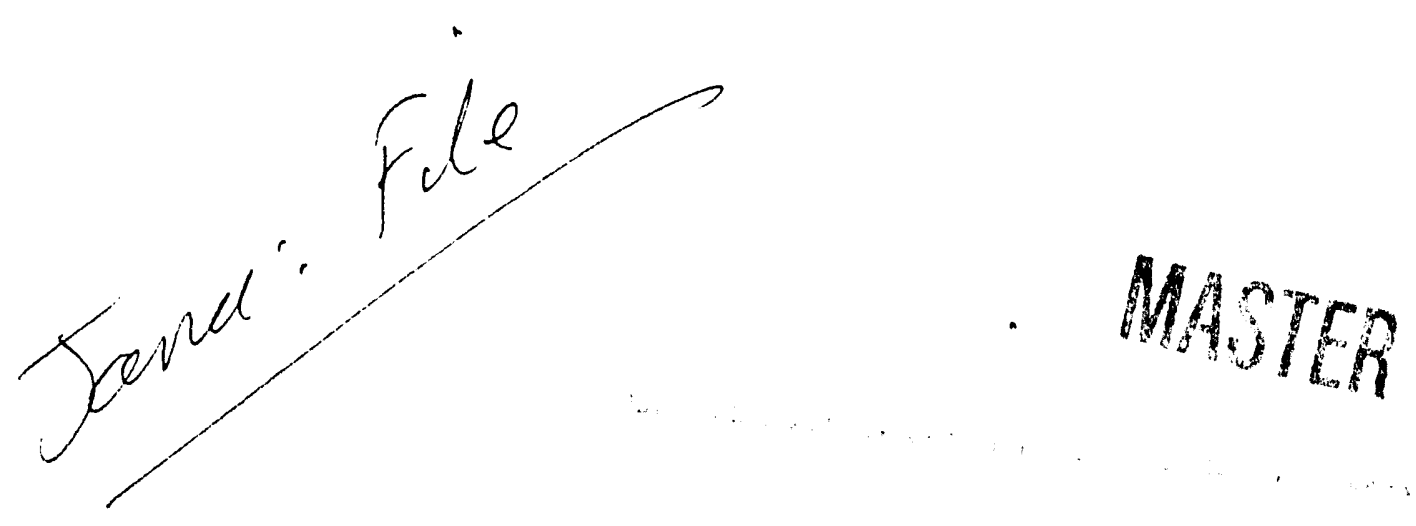


\section{TABLE OF CONTENTS}

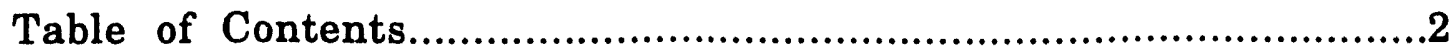

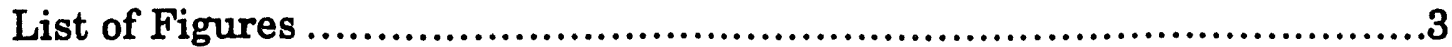

Executive Summary ..............................................................

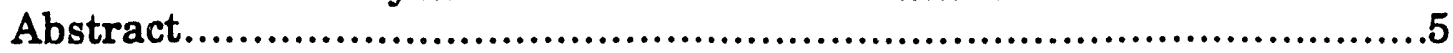

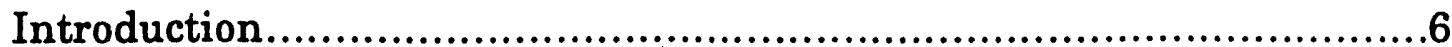

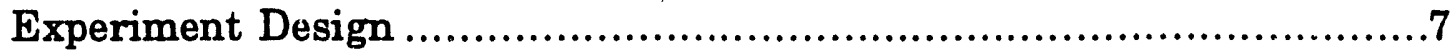

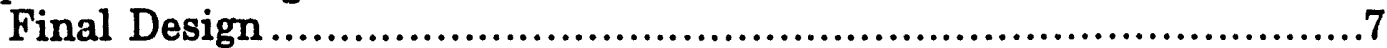

Steady State Mixer .............................................................

Reactor and Related Equipment .........................................12

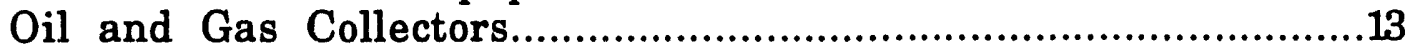

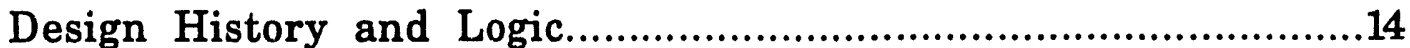

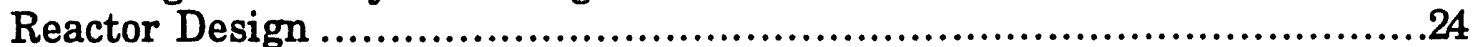

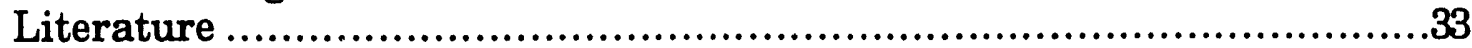

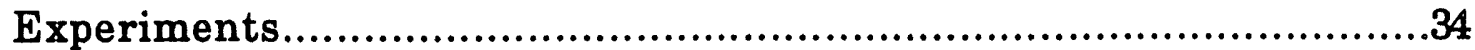

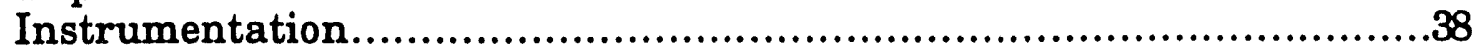

Modelling and Simulation........................................................

Diffusion-limited, Infinite Gas Chamber, Homogeneous Solid

Breakthrough Model ...................................................42

Pseudo-steady state, Diffusion-limited, Homogeneous

Breakthrough Model ..................................................46

Diffusion-limited, Finite Gas Chamber, Homogeneous Solid

Breakthrough Model .....................................................4.6

Pseudo-Steady State Laminae Attack Model ............................48

Rate Limited Reaction Model ............................................52

Stochastic Fissure Model......................................................54

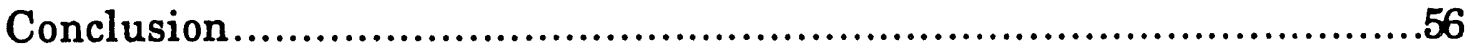

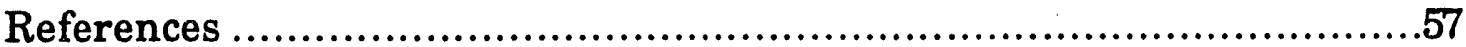




\section{LIST OF FIGURES}

Figure 1. Final Experiment Design..........................................

Figure 2. Chemical Inputs into Reactor.......................................9

Figure 3. Reactor and Related Equipment..................................10

Figure 4. Experiment Collectors. ............................................11

Figure 5. Design for Continuous Reactant Gas Flow. ........................21

Figure 6. Perspective View of Assembled Reactor. .........................25

Figure 7. Cross Section View of Assembled Reactor. .........................26

Figure 8. Bottom Flange of Reactor.................................................27

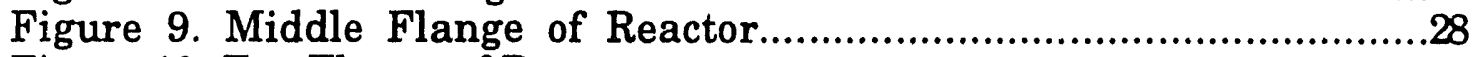

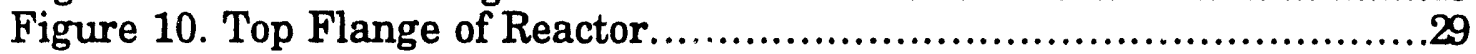

Figure 11. Core Holder Modification Detail........................................31

Figure 12. Sample Loop Diagram...........................................39

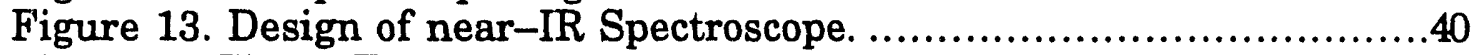

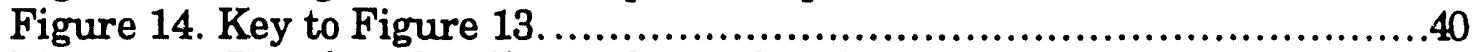

Figure 15. Results of Diffusion-limited, Infinite Gas Chamber, Homogeneous Solid Breakthrough Model.....................................44

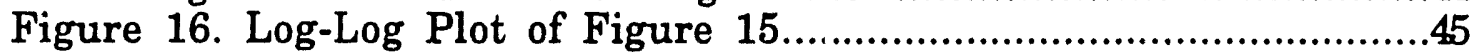

Figure 17. Uneven Grid. .....................................................46

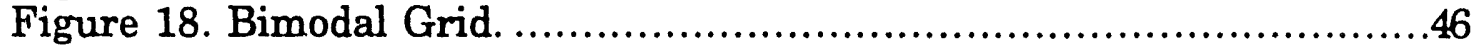

Figure 19. Results of Diffusion-limited, Finite Gas Chamber, Homogeneous Solid Breakthrough Model ..................................47

Figure 20. Breakthrough Time versus Reactor Size.........................48

Figure 21. Results of Pseudo-Steady State Laminae Attack Model. ..........51

Figure 22. Node Point Labelling. ................................................52

Figure 23. Examples of Fissure Enhanced Breakthrough. ..................55 


\section{EXECUTIVE SUMMMARY}

This report covers the status of DOE project (Award Number DE-AC2289BC14479; UCB Account Number 153-6529). The research project supported was the investigation of a chemically assisted in situ oil shale extraction method, involving lower temperature and pressure than existing procedures, with the goal of developing an economically viable recovery method.

Prior research at the Argonne National Laboratory had indicated that acid attack of oil shale unexpectedly increased the yield of bitumen by $80 \%$. Follow-up research at the University of Colorado-Boulder, Department of Chemical Engineering determined that under static, equilibrium/end-point reaction conditions, yields of $80 \%$ of Fischer Assay could be achieved with $10 \%$ hydrogen chloride $(\mathrm{HCl}), 80 \%$ steam $\left(\mathrm{H}_{2} \mathrm{O}\right)$, and $10 \%$ carbon dioxide $\left(\mathrm{CO}_{2}\right)$ at moderate pressure $(600 \mathrm{kPa})$ and temperature $(588 \mathrm{~K})$. Published results from Argonne and Lawrence Livermore indicate that at $588 \mathrm{~K}$, no more than $18 \%$ of Fischer Assay should be expected.

The purpose of the research was to determine two things: if similar results could be obtained from $10 \% \mathrm{HCl}, 80 \% \mathrm{H}_{2} \mathrm{O}$, and $10 \% \mathrm{CO}_{2}$ at $600 \mathrm{kPa}$ and $588 \mathrm{~K}$ under dynamic, non-equilibrium conditions (penetrating into solid oil shale) and if the process was likely to be scalable to field-production sizes.

Our research has determined that recoveries under dynamic conditions can near, or exceed, those under static, end-point conditions. Furthermore, our results imply that it is possible, if not likely, that the process is scalable to the field.

These conclusions are based on the our experimental results. The recovery from Experiment \#10 is estimated to be $90 \%$ of Fischer Assay. The oil shale core breakthrough times are random, indicating that the limiting factor is the fissures present in the core, not diffusion.

Based on our results, we have some recommendations. An element analysis should be performed to determine the final location of the chlorine atoms. The kinetics and stoichiometry of the reactions between $\mathrm{HCl}, \mathrm{H}_{2} \mathrm{O}$, and $\mathrm{CO}_{2}$ and oil shale (including kerogen) should be determined experimentally. The kinetics should be used to determine the precise penetration acceleration caused by the fissure. More experiments should be performed on laboratory scale, and the results used to more accurately determine the feasibility of further experimentation on rarger scales. 


\begin{abstract}
The purpose of the research project was to investigate the feasibility of the chemically assisted in situ retort method for recovering shale oil from Colorado oil shale. The chemically assisted in situ procedure uses hydrogen chloride $(\mathrm{HCl})$, steam $\left(\mathrm{H}_{2} \mathrm{O}\right)$, and carbon dioxide $\left(\mathrm{CO}_{2}\right)$ at moderate pressure to recovery shale oil from Colorado oil shale at temperatures substantially lower than those required for the thermal decomposition of kerogen. The process had been previously examined under static, reaction-equilibrium conditions, and had been shown to achieve significant shale oil recoveries from powdered oil shale. The purpose of this research project was to determine if these results were applicable to a dynamic experiment, and achieve penetration into and recovery of shale oil from solid oil shale.
\end{abstract}

Much was learned about how to perform these experiments. Corrosion, chemical stability, and temperature stability problems were discovered and overcome. Engineering and design problems were discovered and overcome.

High recovery (90\% of estimated Fischer Assay) was observed in one experiment. Significant recovery (30\% of estimated Fischer Assay) was also observed in another experiment. Minor amounts of freed organics were observed in two more experiments. Penetration and breakthrough of solid cores was ıbserved in six experiments. 


\section{INTRODUCTION}

Previous research by Vandegrift, et alia [1] at the Argonne National Laboratory suggested that a increase in oil recovery from Colorado oil shale bitumens (from $10 \%$ to $18 \%$ of Fischer Assay) may be obtained by acidification. Exploratory research by Blakeley [2] determined determined that a mixture of $10 \% \mathrm{HCl}, 80 \% \mathrm{H}_{2} \mathrm{O}$, and $10 \% \mathrm{CO}_{2}$ at $600 \mathrm{kPa}$ and $588 \mathrm{~K}$ resulted in shale oil recoveries exceeding $80 \%$ of Fischer Assay ${ }^{1}$ after the reactions ran to equilibrium. Blakeley used powdered Colorado oil shale, and obtained an oil identical to that produced by thermal decomposition.

Ordinary oil shale recovery procedures use one of two methods. The first procedure, in situ and modified in situ retorts, uses an underground combustion front, possibly enhanced by partial mining and rubblization of the formation, to thermally decompose the kerogen into flowable oil. The second procedure, ex situ retort, uses an above-ground retort to thermally decompose the mined oil shale into oil and waste slag. Both procedures require require temperatures above $750 \mathrm{~K}$. Both procedures are not competitive with crude oil because of process expenses (e.g., mining) and/or process inefficiencies (e.g., ground sweep limitations caused by formation isolation).

The chemically assisted in situ procedure may be able to avoid the above deficiencies, provided several criteria are met. First, the procedure must be capable of penetrating into solid oil shale with reasonable speed. Second, the penetration process must not be diffusion limited, but must be limited be another (faster) mechanism. Third, the recovery efficiency of the procedure must be at least $80 \%$ of Fischer Assay. Fourth, the oil produced must not contain chlorinated hydrocarbons - the chlorine atoms must remain in the inorganic phase.

The purpose of the research project was to investigate in the laboratory the feasibility of the chemically assisted in situ retort method for recovering shale oil from Colorado oil shale. Specifically, the purpose of the research was to provide answers to those questions posed in the previous paragraph.

The research project may be divided into a number sections: Experiment Design, Reactor Design, Literature, Experiments, and Modelling.

\footnotetext{
${ }^{1}$ The Fischer Assay of Blakeley's oil shale was $137.7 \mathrm{~mL} \mathrm{~kg}^{-1}$.
} 


\section{EXPERIMENT DESIGN}

A first year graduate student, S. J. Kassarjian, in the Department of Chemical Engineering at the University of Colorado at Boulder was accepted for the project in February, 1990. The student has a B.S.E in Chemical Engineering from the University of Michigan at Ann Arbor, and was especially suited for the project based on previous experiences in porous media, core flooding (secondary oil recovery), kinetics, thermodynamics, and modelling from research with Professor H. Scott Fogler (Chair, Department of Chemical Engineering, University of Michigan-Ann Arbor) and with Haldor Topsøe A/S, Lyngby, Denmark. S. J. Kassarjian intended from the beginning to earn a Ph.D. in Chemical Engineering; the potential for extending the study to include modelling and optimization of the recovery technique in a doctoral thesis was excellent.

\section{FINAL DESIGN}

The final design of the experimental equipment is shown in Figure 1. Various subsections are detailed in the following figures.

The entire final design is shown in Figure 1. The final design may be separated into several major units: Steady State Mixer, Reactor, and Oil Collection. There are several minor units: Vacuum, Gases, and Computer. The major sections are shown separately in Figures 2-4. For convenience, the divisions between the sections shown in Figures 2-4 differ slightly from the divisions shown in Figure 1.

\section{STEADY STATE MIXER}

The Steady Siate Mixer is shown in Figure 2 . The primary purpose of the Steady State Mixer is to provide a steady state stream of gases by mixing $\mathrm{HCl}, \mathrm{H}_{2} \mathrm{O}$, and $\mathrm{CO}_{2}$ in controlled quantities and heating the gases to the operating temperature of the reactor. The Steady State Mixer is essential for the Chemical Flood procedure. The secondary purpose of the Steady State Mixer is to allow the reactor gas chamber to be filled with a particular gas at a selectable temperature up to a controlled pressure - this is necessary for the Chemical Soak procedure.

The Steady State Mixer uses mass flow controllers to maintain a steady, controlled flow rate of both $\mathrm{HCl}$ and $\mathrm{CO}_{2}$. Both gases are supplied to the system from ordinary gas cylinders, which are stored in a fume hood for safety reasons. 


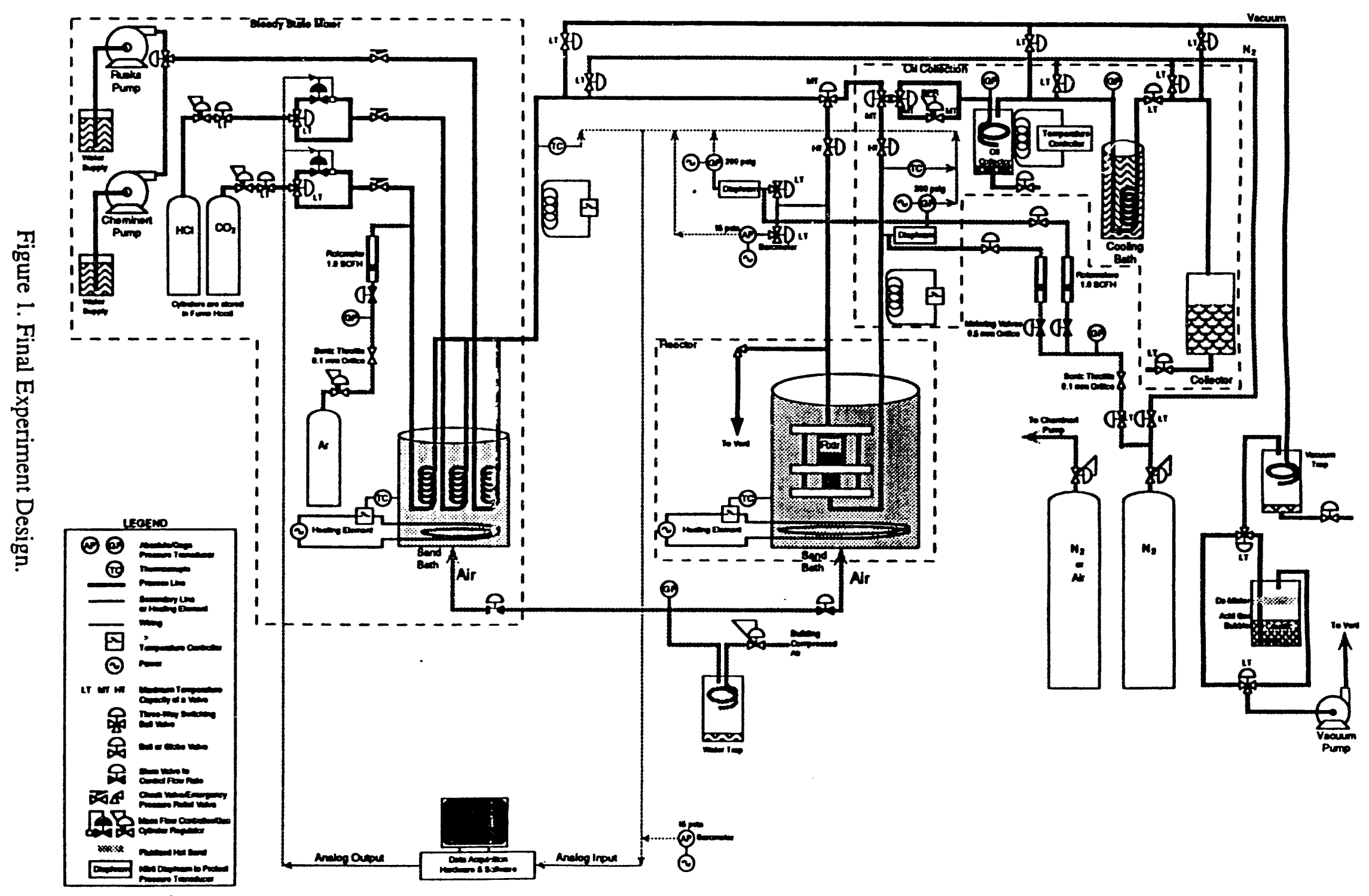




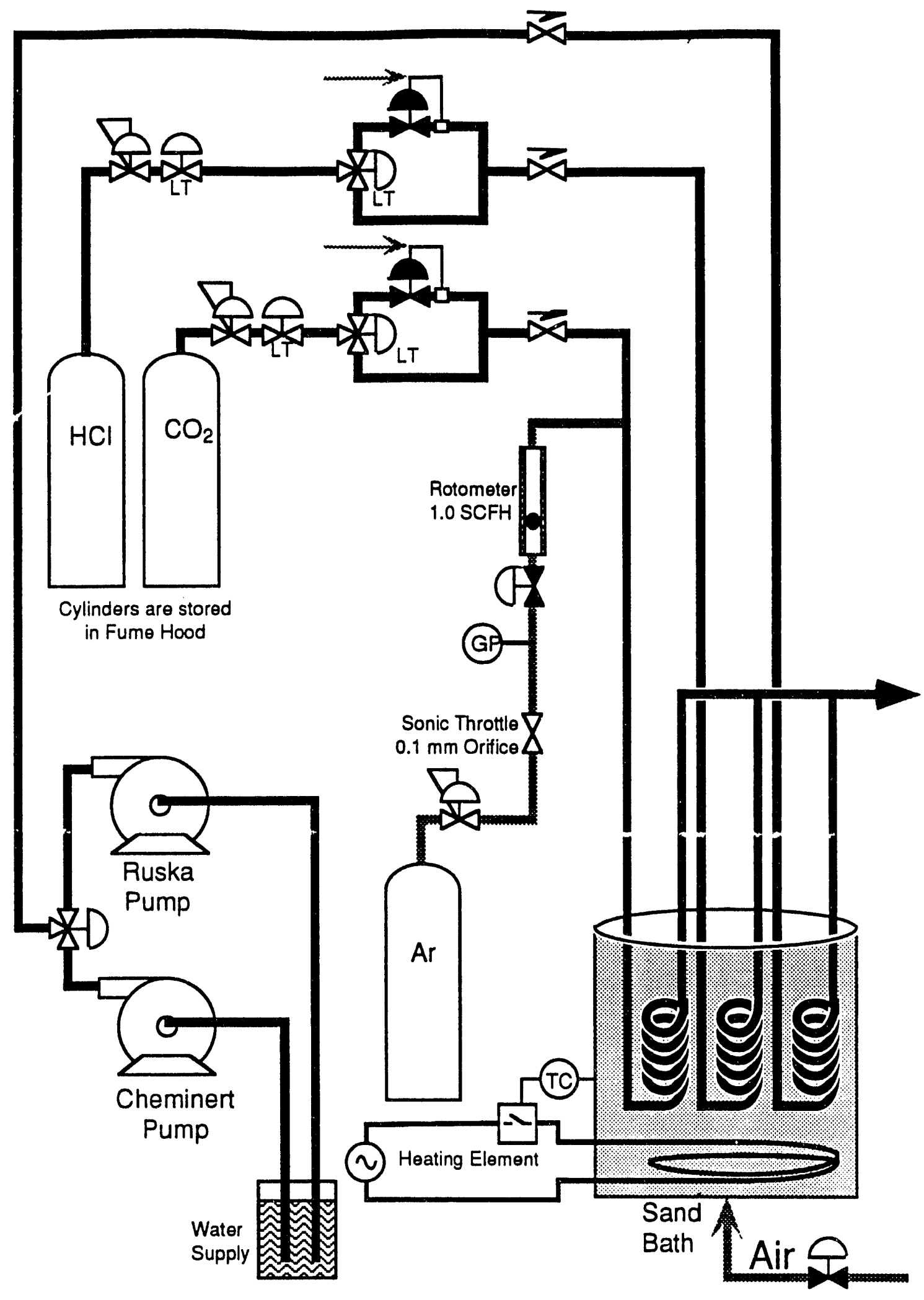

Figure 2. Chemical Inputs into Reactor. 


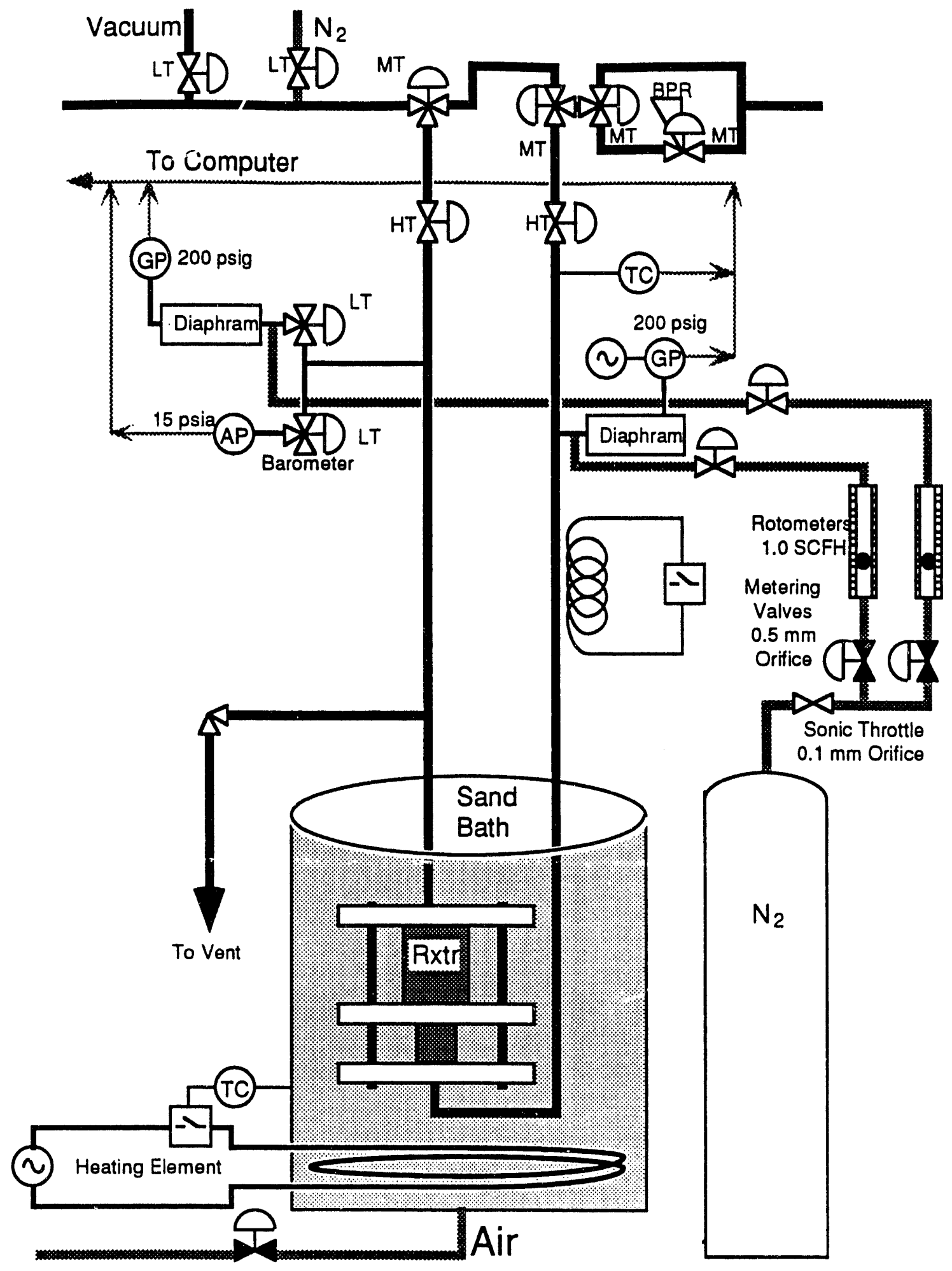

Figure 3. Reactor and Related Equipment. 

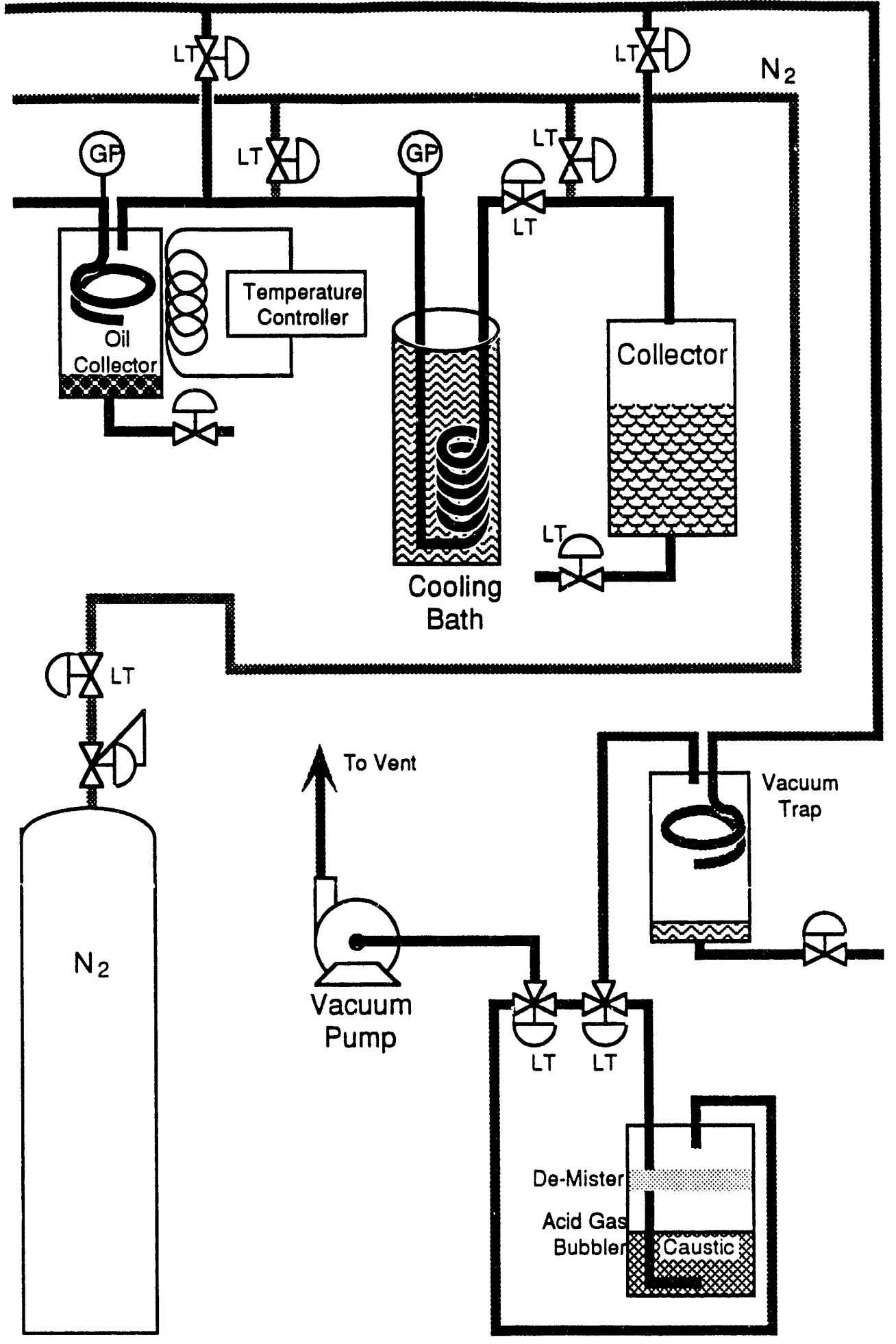

Figure 4. Experiment Collectors. 
Water flow during steady state operation is maintained by a Cheminert pump. A Cheminert pump is a positive displacement, dual cylinder pump capable of and very precision and accurate liquid flows, and may be used with water and a wide range of organic solvents. Cheminert pumps were designed primarily for liquid chromatography applications, but are quite suitable for our system, provided the system pressure is less than $100 \mathrm{psig}$ and the required flow rate is less than $2 \mathrm{~cm}^{3} \mathrm{~min}^{-1}$.

For non-steady operation, a positive displacement cylinder, single barrel Ruska pump is used. Ruska pumps were designed for core flooding experiments, where constant volume flows at high pressure and high flow rates are required. Because the Ruska pump has only one cylinder, it is not capable of steady state flows because the cylinder must be periodically refilled. The Ruska pump has two advantages over the Cheminert pump: higher pressure (up to $1000 \mathrm{psig}$ ), and higher flow rates (approximately $1000 \mathrm{~cm}^{3} \mathrm{~min}^{-1}$.

An argon flow stream was designed to provide a inert standard stream. The argon is inert within our system, and will provide information on the relative flow rates of all of the exit gases during steady state operation when the exit gas composition is determined by a gas chromatograph. A sonic throttle followed by a fine needle valve and a rotometer will provide precision control over the flow rate.

All three flows then pass through a check valve to minimize corrosion damage. Then the gases and water streams enter a fluidized sand bath. The sand bath is heated, and the fluidized sand provides excellent heat transfer and temperature uniformity. Sand bath temperature is controlled with commercial analog temperature controllers. The fluidizing gas is building air. Only after heating are the gas streams mixed. The mixing is accomplished solely by joining the tubes with ordinary union tees. The gas mixture then proceeds to the reactor.

\section{REACTOR AND RELATED EQUIPMENT}

The reactor is fully described in the section, Reactor Design. Here, the reactor and its related equipment are shown together in Figure 3. The assembled reactor is heated in another fluidized sand bath. This sand bath is larger than the one used to preheat the gas mixture, but is otherwise similar.

The gas flow from the Steady State Mixer is kept hot by heating the tubing with electrical resistance heating tape. Keeping the gases and tubing hot is necessary to prevent catastrophic corrosion failure. If the tubing and gases fall beneath a certain temperature (which is above the condensation temperature of the mixture) corrosion becomes significant. The tubing that carries the reactive gas mixture has both vacuum and nitrogen available for purging. 
The flow then passes through a medium-temperature three-way switching valve. This valve allows the gas chamber to be later emptied to the Oil and Gas Collection section while performing the Chemical Soak. A high-temperature valve seals off the reactor for the Chemical Soak procedure, and protects the three-way switching valves. The three-way valve at the immediate exit from the reactor selects which flow to proceed to the collectors. The next three-way switching valve allows the back pressure regulator to be by-passed when emptying the gas chamber from a Chemical Soak procedure.

When breakthrough occurs, the Chemical flood procedure begins. The high temperature valves are opened, the three-way valves are set to direct the flow through the reactor, and the exit flow is directed through the backpressure regulator. The back-pressure regulator maintains the upstream pressure at its set point, which keeps the reactor at the operating pressure without the use of the valves.

There are several pressure transducers for measuring the pressure in the gas chamber and the pressure at the reactor exit. The pressure transducers are protected from corrosion in two ways. First, a steady state sweep flow of nitrogen is introduced near the transducers. The nitrogen sweeps the corrosive gases down back towards the reactor. A sonic throttle, fine needle valves, and rotometers are used to precisely set the nitrogen flow rate to very low levels (so that the nitrogen flow does not interfere with the pressure transducer measurements).

Unfortunately, the nitrogen sweep may not be used during Chemical Soak, because the reacior is sealed and the nitrogen would cause the system pressure to rise. The second transducer protection method is necessary here. A Viton rubber diaphragm isolates the transducer from the corrosive gases. Previously, nitrile ruiber diapiragms were useu. However, nitrile rubber was attacked by the corrosive gases and the shale oil vapor. Thus replacement was necessary.

The tubing exiting from the reactor is also heated with electrical resistance heating tape. Without this heating, the shale oil shows a tendency to freeze in the tubing, closing off the reactor exit.

A pressure relief valve is present on the reactor gas chamber to protect against run-away pressure rise. The valve exits to the hood for safety.

\section{OIL AND GAS COLLECTORS}

The Oil Collector and the Vacuum minor unit are shown together in Figure 4. The gases collected from the reactor are treated identically, whether the gases came from the gas chamber during the Chemical Soak or from the reactor exit during a Chemical Flood.

The gases first enter a glass cyclone in order to separate the shale oil from the other gases. Condensible and non-condensible gases are separated 
by the cyclone by simple gravity. The cyclone is of course considerable cooler than the reactor, so the shale oil condenses. The cyclone is heated with electric resistance heating tape and controlled to $100^{\circ} \mathrm{C}$ with a commercial analog temperature controller so that any condensed water is evaporated.

The gases that do not condense in the cyclone are then cooled in a water bath. The bath is filled with cold tap water, so most of the steam condenses here, to be collected down stream.

Vacuum and nitrogen is provided in several locations. In practice, vacuum was only pull from the final collector when the pressure rose above atmospheric. Nitrogen was rarely (if ever) used.

Because of the corrosivity of the gases, steps were taken to protect the vacuum pump from damage. First, the vacuumed gases pass through another cyclone to remove any liquid. Then, under ordinary use, the gases are bubbled through a caustic solution of sodium (or potassium) hydroxide. The caustic is non-volatile and posses no danger to the vacuum pump. Any acid gas in the vacuum stream (e.g., $\mathrm{HCl}$ and $\mathrm{CO}_{2}$ ) react with the hydroxide, forming non-volatile salts. These salts remain in solution where they cannot harm the vacuum pump. Stainless steel wire mesh and wadded screen trap any mist, further protecting the vacuum pump. A bypass was built around the acid-gas bubbler so that vacuum beyond the vapor pressure of water would be available.

\section{DESIGN HISTORY AND LOGIC}

The initial designs of the experiments, the reactor, the instrumentation, and the modelling were all based on the assumption that the organic material in oil shale undergoes the following reactions.

$$
\begin{array}{lr}
2 \mathrm{HCl}+\mathrm{CaCO}_{3} \mathrm{Mg}\left(\mathrm{CO}_{2} \mathrm{R}\right)_{2} \rightarrow \mathrm{CaCO}_{3}+\mathrm{MgCl}_{2}+2 \mathrm{RH}+2 \mathrm{CO}_{2} & \text { Rxn } 1 . \\
\mathrm{H}_{2} \mathrm{O}+\mathrm{CaCO}_{3} \mathrm{Mg}\left(\mathrm{CO}_{2} \mathrm{R}\right)_{2} \rightarrow \mathrm{CaCO}_{3}+\mathrm{MgO}+2 \mathrm{RH}+2 \mathrm{CO}_{2} & \text { Rxn } 2 . \\
2 \mathrm{HCl}+\mathrm{M}^{2+} \mathrm{CO}_{3} \rightarrow \mathrm{M}^{2+} \mathrm{Cl}_{2}+\mathrm{CO}_{2}+\mathrm{H}_{2} \mathrm{O} & \text { Rxn 3. }
\end{array}
$$

Proton sources $\left(\mathrm{HCl}\right.$ or $\left.\mathrm{H}_{2} \mathrm{O}\right)$ decompose the bonds between carboxylic acid and mineral carbonates, releasing $\mathrm{CO}_{2}$ and free oil.

An experimental design was among the first choices made. Two previous designs centered on radial flows of the reactant gases. The first design was essentially a hollow core reactor (hollow cylinder geometry), but was rejected in preference for a disk geometry. The current reactor design is based on linear flow through a cylinder, which is much easier to work with experimentally. Also, the mathematical analysis of linear flow through a cylinder is more revealing of the reaction mechanisms [3]. The current design was simpler and had a reduced potential for creating difficulties during experiments, which would delay progress. 
An early hindrance was related to materials of construction-the experimental conditions in the reactor are far harsher than researchers in the petroleum industry normally work with. The experimental conditions are approximately $588 \mathrm{~K}$ with steam, $\mathrm{CO}_{2}$, and $\mathrm{HCl}$ at about 6 bar. Most commercial epoxies can not handle the temperature. Two potential alternatives first considered were molten lead or a phenolic resin and silicone copolymer. Adhesive manufacturers were contacted in hope of finding a suitable potting material. A firm that specialized in exotic epoxies was found: Cotronics, Inc. of Brooklyn, NY. A selection of flowable epoxies was purchased for testing.

Experimental procedures were then developed. Gias temperature, pressure, and composition were to be monitored during the reaction, and would be examined upon breakthrough. The oil would be recovered using hot water or steam. The resultant recovery from the core would then be examined for gas composition, oil and wax properties, and dissolved salts in the water.

Literature was consulted for relevant previous work on solid-gas reactions. Very little was found that was directly relevant to oil shale reactions.

Following the first three experiments, modifications were designed for subsequent experiments. The temperature was to increase to $325^{\circ} \mathrm{C}$. Ceramic potting was to be used to bond the shale core to the core holder. A cyclone-type separator was be installed in the vacuum line upstream of the acid trap to prevent "huffed" material from being collected within the acid trap and mixed in the strong caustic therein.

The discovery of the volume expansion raised the concern that the oil sinale permeability might not increase with the progressivil of the iedition front. Later experiments indicate that this is not a concern.

Based on visual examination of the reacted core, the proposed chemical reaction, and reported kerogen structure, it was conjectured that two mechanisms (steps) might be necessary for the production of free oil. The first step would be the chemical freeing of the organics by the previously noted rear'ion:

$$
\begin{array}{ll}
2 \mathrm{HCl}+\mathrm{CaCO}_{3} \mathrm{Mg}\left(\mathrm{CO}_{2} \mathrm{R}\right)_{2} \rightarrow \mathrm{CaCO}_{3}+\mathrm{MgCl}_{2}+2 \mathrm{RH}+2 \mathrm{CO}_{2} & \text { Rxn } 1 . \\
\mathrm{H}_{2} \mathrm{O}+\mathrm{CaCO}_{3} \mathrm{Mg}\left(\mathrm{CO}_{2} \mathrm{R}\right)_{2} \rightarrow \mathrm{CaCO}_{3}+\mathrm{MgO}+2 \mathrm{RH}+2 \mathrm{CO}_{2} & \text { Rxn } 2 .
\end{array}
$$

The second step would be the catalytic cracking of non-flowing $\mathrm{RH}$ to smaller and flowable QH

$$
\mathrm{RH} \rightarrow \mathrm{QH}+\mathrm{Q}^{\prime} \mathrm{H}
$$

Rxn 4.

which decreases the saturation or 
which does not change the amount of saturation.

The third important observation was that the oil shale is not only heavily striated, but also contains cracks. Every core sample that was prepared had communication between the two ends - in other words, bulk convective flow was possible through the core. Even cores with no visible cracks had communication between the two faces. Unfortunately, in every case, the communication disappeared when the core was heated to reaction temperature. Thus the obvious and desirable reaction method of continuous flow through the core was not possible and the huff-and-puff strategy was employed.

The original design of the process was completed, pending necessary modifications when more was learned of the process itself. The reactant gases, $\mathrm{HCl}$ and $\mathrm{CO}_{2}$, were to be mixed in a pressure vessel (a Hastelloy $\mathrm{C}$ bomb) at ambient temperature and the appropriate pressure to achieve the desired molar ratios. Water would then be pumped into the bomb, via an oilwater reservoir served by a Ruska volumetric pump. The bomb, residing in a second fluidized sand bath, would be heated to process temperature. The $\mathbf{r} \in$ actor gas chamber, after evacuation, was also to be heated to temperature. The reactor gases were to be introduced and the reaction(s) begun.

Because the original expected reaction stoichiometry was one mole oil vapor evolved per one mole gas consumed, the reactant gas chamber pressure was expected to remain constant. Upon breakthrough of the reactant gases, the down-side of the core would be sealed-off. The remaining reartant, gases (and produrt gases that have back-diffused to the chamber) would then be drawn off and sampled for quantitative analysis by gas chromatography for $\mathrm{HCl}, \mathrm{CO}_{2}, \mathrm{H}_{2} \mathrm{O}$, sulfur compounds, and light hydrocarbons. The gases would then be cooled, condensed, and collected. To recover the released hydrocarbons, the core would then be flooded with hot water or steam. The secondary-type recovery would be done at a lower temperature than the reaction, with the temperature of the $\mathrm{H}_{2} \mathrm{O}$ and of the core maintained by the fluidized sand baths ${ }^{1}$.

At this point, we began to consider the actual layout of equipment within the laboratory. The University's Environmental Health and Safety department was consulted. Some modifications suggested by Steve Robinson of the University's Environmental Health and Safety Department and Professor Ron West of the Department of Chemical Engineering at the University of Colorado included: increasing the distance between the gas

\footnotetext{
${ }^{1}$ As might be expected, the design of the reaction equipment and the process changed considerable over time.
} 
cylinders and the fluidized baths, and adding pressure relief valves to the reactor gas chamber and the bomb.

Reactor construction was started with the assistance of the Chemical Engineering Instrument Shop Foreman, Willy Grothe. The Western Research Institute (WRI) of Laramie, Wyoming agreed to supply oil shale blocks of different shale oil yields.

The design work was completed with a experiment safety inspection . The final experiment set-up is shown in Figure 1.

A significant change was introduced into the experiment procedure itself. We reasoned that the competing reaction (Reaction \#3) would be quickly quenched by reaching equilibrium. (All three reactions produce $\mathrm{CO}_{2}$, additionally inhibiting the competing reaction) ${ }^{1}$. Thus the addition of $\mathrm{CO}_{2}$ to the reaction system was thought to be unnecessary and this would allow the experimental procedure to be made more convenient. The original procedure was to load the pressure bomb with the appropriate amounts of $\mathrm{CO}_{2}, \mathrm{HCl}$, and $\mathrm{H}_{2} \mathrm{O}$, heat the mixture to $588 \mathrm{~K}$, and then flow the gas reactants to the reactor after everything had reached the operating temperature. Under the new procedure, the bomb was eliminated: $\mathrm{HCl}$ would flow directly to the reactor until the appropriate pressure was obtained, and then high pressure steam would be injected directly into the reaction chamber. Steam was to be made by pumping distilled water from a Ruska pump through stainless steel tubing coils immersed in the smaller fluidized sand bath heater.

The original purpose for premixing and preheating the reactants was to create an instantaneous starting time at the reaction temperature. It was felt that the above procedure would be adequately instantaneous, especially because ihe shale cure wouiu diready lu at tile leaction ternperature. The only caveat was that the loss of $\mathrm{HCl}$ due to reaction $\# 3$ might be larger than expected. The actual procedure adopted was quite similar to the above procedure. First, $\mathrm{CO}_{2}$ would be loaded into the reactant chamber of the reactor, followed by $\mathrm{HCl}$, and finally the steam to the final pressure. Oxidation reactions were prevented by maintaining a vacuum on the reactor gas chamber prior to adding the reactant gas mixture. A later literature search discovered published kinetics for the inert-atmosphere pyrolysis of oil shale; at $588 \mathrm{~K}$, negligible decomposition may be expected in the time required to bring the reactor to operating temperature.

\footnotetext{
${ }^{1}$ Later equilibrium calculations indicated that the equilibrium partial pressure of $\mathrm{HCl}$ (from one particular reaction between $\mathrm{HCl}$ and a mineral carbonate) was so small that this experiment procedure was likely to fail. Nevertheless, the general idea was adopted because it simplified the process.
} 
The Swagelok fittings on the reactor that were heavily used (i.e., the fittings used to connect the reactor to the system) were replaced with Cajun fittings, which have a much higher duty cycle. This helped to limit leaks.

The mineral oil-water reservoir has been removed because of the unreliability of the plastic bags separating the oil and water phases. Instead the Ruska pump will pump water directly into the system. Precautions have been taken to prevent any $\mathrm{HCl}$ from entering the pump.

Initial designs to modify the system to allow continuous flow of reactant gases were constructed. Mass flow controllers with check valves will maintain gas flow to match the water flow rate from the Ruska pump. A back pressure regulator limits the flow of reactant gases from the downside of the reactor.

Experiment \#5 revealed three experiment design flaws. A SS316 stainless steel union suffered corrosion failure. The minimal amount of recovered shale oil lead to forced us to rethink the flow pathway. The silicon rubber sealant was observed to have undergone chemical degradation.

The failure of the union, made of SS316 stainless steel (which is rather immune to $\mathrm{HCl}$ attack even at $325^{\circ} \mathrm{C}$ ) during Experiment \#5, is believed to have been triggered by the failure of a thermocouple (TC) that had its tip located within the fitting. The TC sheath is of SS304 type stainless steel, which is more susceptible to $\mathrm{HCl}$ at $325^{\circ} \mathrm{C}$. The failure of the TC sheath released the contents of the TC to the reactor. The TC filler reacted with the reactant gases in a highly exothermic reaction. The local temperature extreme, which may have exceeded $1000^{\circ} \mathrm{C}$, greatly accelerated the attack of $\mathrm{HCl}$ on the fitting and subjected the fitting to thermal stresses much in excess of its capabilities. There are a number of indications to support the above curiclusions. The prinnary is that shurily before the $\mathrm{TC}$ and unicn failed, the TC indicated a very swift rise in temperature, from approximately $200^{\circ} \mathrm{C}$ (the steady average over 48 hours) ${ }^{1}$, to above $600{ }^{\circ} \mathrm{C}$ linearly, to $1370{ }^{\circ} \mathrm{C}$ (DAP TC full scale) exponentially. The second indication is that failed TC is missing $5 \mathrm{~cm}$ of sheath from the tip, but the Chromel and Alumel TC wires remain intact (but not the TC junction). The use of SS304 sheathed TC's was a design flaw, and the TC's needed to be replaced. Inconel sheathed TC's have been ordered.

The second design flaw would severely limit the amount of shale oil freed by chemical reaction that can be removed from the reactor. There are two design modifications. The first is a large reduction in the internal diameter of the tubing that will carry the oil vertically from the bottom of the reactor up and out of the sand bath. A large diameter tubing would not be able to carry the liquid from a gas-liquid mixture vertically because the gas

\footnotetext{
1The union and TC tip were located approximately $20 \mathrm{~cm}$ above the fluidized-sandbath's surface.
} 
will bubble through the liquid. A small diameter tube prevented this. The original tubing was $1 / 4$ inch and was replaced with $1 / 8$ inch tubing with 0.049 inch walls, giving an 0.027 inch ID.

Another design modification was the addition of a Pyrex glass cyclone that separates shale oil from spent reaction gases. The cyclone is placed as close to the reactor as possible to limit the possibility of oil clogging tubing. Pyrex allows visual observation of the collected oil, yet does not require protection from the hot oil (as any polymer would).

A third problem was observed in the silicon rubber sealant. Silicon rubber sealant was used to seal the pipe threading joining the Cajun VCR joint to both the top and bottom flanges of the reactor. After cool down, it was observed that what little of the silicon rubber at top flange remained was brittle, while the silicon rubber on the bottom flange was intact and still flexible. It is concluded that silicon rubber stalant is able to handle high temperatures, but is quite susceptible to the reactant gas mixture at high temperature. The pipe fitting-to-Cajun VCR adaptor has been replaced by welding $1 / 4$ inch tubing directly to the top flange.

Experiment \#6 revealed the corrosion problem was more severe than previously thought. Severe and recurrent corrosion of experimental equipment became a problem after the experimental temperature was increased to the optimal temperature determined by Blakeley (from $560 \mathrm{~K}$ to $600 \mathrm{~K}$ ). The corrosion was apparently caused by the extreme thermal gradient introduced by increasing the sand bath temperature to $600 \mathrm{~K}$. The thermal gradient was sharpened by a insulating cover used primarily to contain sand thrown from the bath by violent fluidization. Swagelok fittings, Cajun VCR fittings, SS316 stainless steel tubing $\left(0.045^{\prime \prime}\right.$ wall), SS304 stainless steel sheathed thermocouples, and an Inconel sheathed thermocouple all failed due to currosion. Furtherwore, ine ivcation of ine failure was always at the location of the greatest thermal gradient. The first solution attempt, which removed the insulating cover (the air flow rate was reduced to minimized thrown sand) and wrapped the tubing with rock wool insulation, failed. The second solution attempt, which replaced the stainless steel tubing with alloy C-276 tubing, and removed all fittings and thermocouples from the area of high thermal gradient (actually from the sand bath), has not failed since its implementation.

Experiment \#6 revealed a second problem was that oil freed from the core did not flow up into the new Pyrex cyclone. Even though oil was freed from the oil shale (found by swabbing out the tubing on the core side of the reactor), none has been recovered in the Pyrex cyclone. There are several possible causes. The first is that the tube internal diameter (ID) is too large; the oil may have coated the inside of the tube instead of flowing up the tube when pressured from below with steam. It was not possible to solve this problem by using a smaller ID tubing because C-276 alloy tubing is not available in $1 / 8$ " OD tubing, and is available for the $1 / 4$ " OD tubing in only one wall thickness $(0.035 ")$. SS316 stainless steel tubing can not be used because of the presence of $\mathrm{HCl}$. $\mathrm{HCl}$ is necessary on the core side of the 
reactor (thus in the tubing) to react the backside of the core. Furthermore, when a very small ID was used (SS316 tubing), the tubing clogged with solids dislodged from the core. It is currently hoped that the small diameter was not the cause of the problem because there appears to be only one possible solution to this problem: flooding the core with water instead of steam. The second possible cause is that the tubing on the core side of the reactor was not heated outside of the sand bath; the oil may have solidified. Electrical resistance heating tape with a temperature controller has been wrapped around the tubing to prevent solidification. The third possible impediment to recovering freed oil was that the tubing was clogged a number of times. (See the Experiments Section.)

The third difficulty was condensation of steam within the Pyrex cyclone. The design called for steam to be condensed in cooling coils (immersed in water) downstream of the Pyrex cyclone, just upstream of the acrylic collection vessel. The probl.em was solved by the installation of electrical resistance heating tape on the tubing above the sand batk. To make certain that water does not collect within the Pyrex cyclone, the bottom of the cyclone has also been wrapped with heating tape. The elevated temperature and vacuum ensures no water remains within the cyclone, even if some steam does condense.

The tubing above the reactor gas chamber (front side) was found clogged several times. Because of the design of the reactor, it is quite improbable that material from the shale core could have travelled upward far enough to clog any tubing. The cause seems to be reaction of the sand (actually alumina) from the fluidized sand baths with the reactant gases. When sand from the sand baths was observed within the water reservoir (probably thrown there by violent fluidization in the sand bath) the Ruska pump and tubing between the pump and the reactor were checked for the presence of sand. Sand was discovered in both and removed. Unfortunately the ñrst cleaning attempt was only partially successfully, resulting in subsequent clogging.

The very small-ID tubing that was installed at the core side of the reactor to minimize the loss of oil also clogged. The apparent cause was particles dislodged from the oil shale. The structure of oil shale is not strong. First, there are numerous strata within the shale, presenting much opportunity for chipping and fragmenting. Second, the yield of shale varies dramatically, even on a small scale. Local concentrations of up to 50 gallons of oil per ton of rock are not uncommon in shale that averages 20-30 gallons per ton. Shale with yields as high as 50 gallons per ton has very little mineral material and is predominantly organic. When the kerogen is mobilized, all that remains is very fine particles (the kerogen was holding these particles together). These particles also could have contributed to clogging the tubing.

When no oil was recovered from the shale in spite of the amount of reaction and the amount of steam flowed through the core, the possibility that the kerogen was freed, but not made flowable, was noted. To at least 
confirm that the kerogen was being freed from the shale, a portion of reacted core was placed in a three stage organic solvent train of cyclohexane, methanol, and methylethylketone. For comparison, a portion of raw oil shale was also placed in a solvent extraction train. The results were the same as observed by Blakeley; from the reacted shale a sizable portion of the organic material was soluble while negligible organic material was recovered (by solvation) from raw oil shale. Specifically, the mass of material extracted from the raw core was negligible (even though the original mass of the raw shale was twice that of the reacted shale), while $0.66 \mathrm{~g}$ of soluble material was extracted from $3.01 \mathrm{~g}$ of reacted core; $21.9 \%$ by mass was extracted from the reacted core.

It was realized that the fissures within the oil shale must be used to facilitate reactive gases transport with convective flow instead of diffusive transport, in order to quickly recover shale oil from the oil shale. To achieve convective flow, a steady state gas mixer was required. The original design to provide steady state flow and controlled mixing of $\mathrm{HCl}, \mathrm{H}_{2} \mathrm{O}$, and $\mathrm{CO}_{2}$ is shown in Figure 5. The final design is shown in Figure 2.

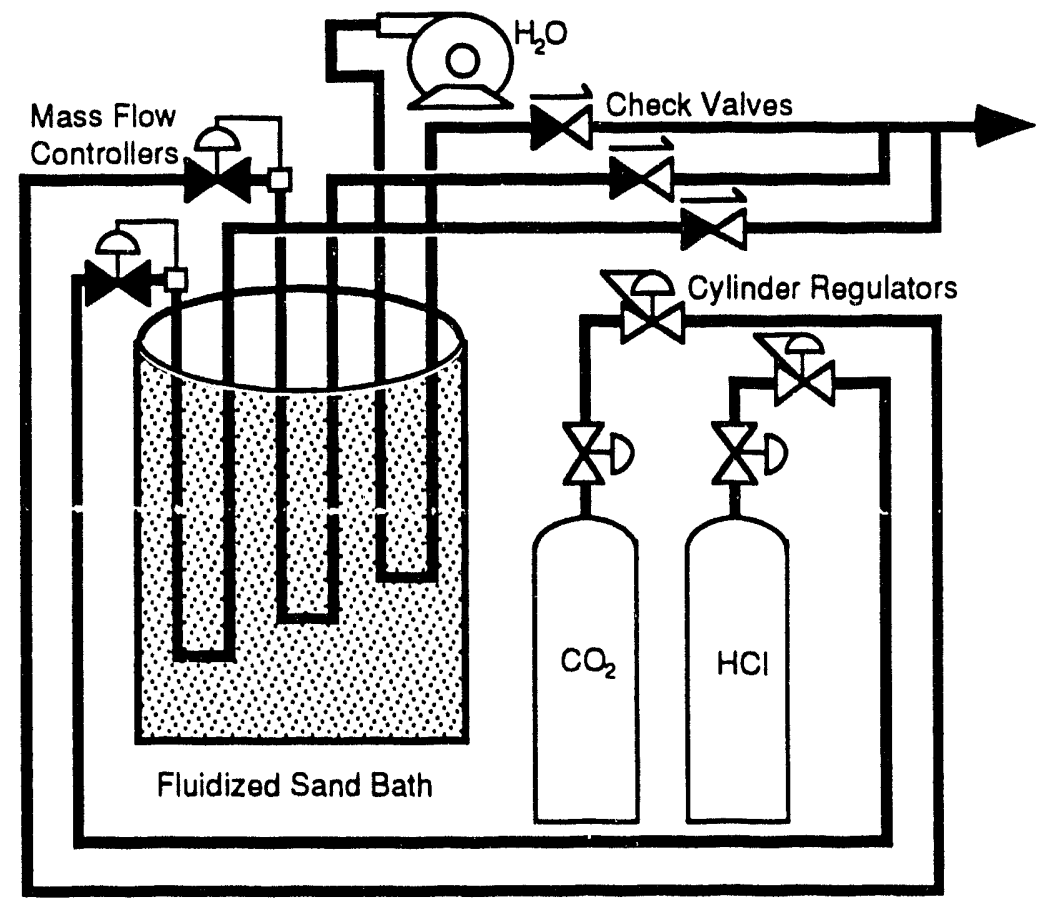

Figure 5. Design for Continuous Reactant Gas Flow.

The various parts include a mass flow controller, calibrated for $\mathrm{HCl}, \mathrm{C}$ 276 alloy tubing, and miscellaneous Swagelok tubing fittings, check valves, and ball valve. An available Cheminert metering pump was used and because the Ruska pump has only one cylinder and is not capable of continuous flow.

Previous experiments recovered shale oil (liquid at ambient temperature) but in limited quantities (approximately $10 \%$ of the total 
organic material). The low yield is probably due to large regions of the oil shale core not being chemically attacked, due to the impermeability of unreacted oil shale matrix. The steady state flow gas mixer allows the rear region of the core to be attacked by fresh reactant gas after breakthrough has been achieved.

It was proposed that the firsures contain high quaitities of organic material relative to the surrounding matrix ${ }^{1}$. Thus the fissures are more readily attacked chemically than the surrounding matrix. Once the organic material within a fissure has been freed by the reaction, the fissure is opened up. Convective flow through the fissure is then possible, allowing the reaction front to penetrate more quickly along the fissures.

Breakthrough is first achieved via the fissures. After breakthrough a slow steady flow of reactant gas will make the r sactant gas uniformly available along the fissure sides, and the reaction front will then proceed orthogonally from the fissures.

'I'he equipment of primary importance for the steady state gas flow experiments is the mass flow controller. The purchased mass flow controller arrived with minimal (useless) documentation. Equally useless telephone help from the manufacturer resulted in a delay of several months while we attempted to have the unit "repaired" by the manufacturer. We eventually got the mass flow to work, without their "assistance."

During Experiment \#10, the units containing nitrile rubber parts failed shortly after chemical flooding began. The two units were replaced by two spare units, which both failed shortly afterwards. The manufacturer recommended Viton rubber replacements.

Viton rubber o-rings and diaphragms were purchased for two pressure transducer protection units. Each unit consists of a single rubluer diaphragm. The system is connected to one side of the unit while the pressure transducer (PT) is connected to the other side. The space above the diaphragm (between the diaphragm and the PT) is filled with an inert liquid (we used light mineral oil).

Additionally, two of the four diaphragm units (made of stainless steel) that were used in Experiment \#10 were found to be significantly corroded. One unit was sufficiently pitted as to require machining before the o-ring grooves would be able to form a reliable seal. The second unit has minor pitting that may have resulted from the unit being cast instead of being entirely machined into shape. The last two units used during the last experiment have not yet been dissembled. Two diaphragm units now have Viton o-rings and diaphragms.

\footnotetext{
${ }^{1}$ A later literature search confirmed this. See the Literature section.
} 
The bottom surface of each diaphragm was caked with solid organic material. Obviously the organic material, though solid at room tempe:ature, is highly volatile at $600 \mathrm{~K}$. In fact this is what caused the tubing to plug at the top of the sand bath (where the temperature controller was not functioning).

A technique used in industry to help protect pressure transducers was considered. A slow-steady stream of nitrogen introduced very near each PT would flush both organics and $\mathrm{HCl}$ back into the reactor. This would protect the PT or the PT protector from chemical attack and minimize the loss of organic material due to condensation in the tubing and PT protector. The easiest way to control the flow rate of the purge stream would be to use a sonic throttle. No problem are foreseen using a purge stream while chemical flooding, but there is a possibility during chemical soak that the nitrogen flow might result in an unacceptable pressure rise in the reactor. The nitrogen purge system was determined to be necessary.

The easiest and cheapest way to control the flow rate of the purge stream would be to use a sonic throttle. The high pressure of the reactor (and the possibility of significant pressure rise) requires that the nitrogen stream have an upstream pressure of at least $150 \mathrm{psig}$. The small reactor volume demands a miniscule flow rate. The largest acceptable sonic throttle would have a diameter of $0.01 \mathrm{~mm}$-the smallest drill bit available is $0.1 \mathrm{~mm}$. A sonic throttle with a $0.1 \mathrm{~mm}$ orifice was constructed, tested, and found (as expected) to flow nitrogen too fast. Thus a sonic throttle will not suffice.

Gases with higher molecular weights were considered (in conjunction with the sonic throttle). The only inert gases heavy enough to significantly reduce the flow rate are xenon and krypton ( 58 mole\% of nitrogen flow). Both are prohibitively expensive (a large cylinder of krypton is about $\$ 6000$ ). Argon is relatively cheap ( $\$ 25$ per large gas cyiinder-nitrogen is $\$ 5$ per cylinder) but only reduces the sonic flow rate to 84 mole\%.

Two metering valves with $0.05 \mathrm{~mm}$ orifices were found. While larger than the sonic throttle, the finely tapered needles allow very good control of the gas flow rate. The size of the valves requires that they be very nearly closed (approximately $1 / 20$ of a turn open); such fine controllability requires observability. Rotometers constructed of polycarbonate polymer were found in the department's "equipment graveyard." These rotometers were rated for use up to $100 \mathrm{psig}$, while the glass rotometers in the "equipment graveyard" were rated to only $50 \mathrm{psig}$. The rotometers will give visual feedback to the metering valve adjustments and are usable at the operating pressure of $600 \mathrm{kPa}$ (about $78 \mathrm{psig}$ ).

The final design is shown in Figure 1. Nitrogen (or perhaps argon) at 150-200 psig flows through the sonic throttle, slightly reducing the pressure. The stream splits, going to each metering valve. Downstream of each metering valve is a rotometer. The rotometers are at the same pressure as the reactor, so urider normal operating conditions their limits should not be exceeded. 


\section{REACTOR DESIGN}

The reactor design was completed quite early. The reactor was designed to provide a constant temperature environment with controlled gas pressure to obtain a linear progression of the reaction interface through the shale core. The reactor was constructed of stock 304 stainless steel and 316 stainless steel tubing. The reactor design consisted of three flange plates (SS304 plate) sealing two cylindrical chambers (SS316 tubing) with silicon rubber gaskets ${ }^{1}$. Threaded stock provided the necessary compression on the gaskets. See Figures 6-10.

Figure 6 offers a perspective view of the assembled reactor, while Figure 7 shows a cross-sectional view of the assembled reactor. The reactor consists of three flanges, two sections of tubing, metal o-rings, and threaded stock and nuts to hold everything together. The two sections of tubing are sandwiched between the three flanges. Each flange has one or two 0-ring grooves, where the metal o-rings sit.

The large cylindrical (upper) section is the gas chamber. The tubing is $76 \mathrm{~mm}$ OD SS316 stainless steel tubing with $6.4 \mathrm{~mm}$ thick walls, and is $85 \mathrm{~mm}$ long. A baffle was installed inside to prevent pieces of oil shale from being carried to the top of the gas chamber and into the tubing, and clogging the tubing.

The smaller cylindrical (lower) section is the oil shale core holder. The cylinder of oil shale is glued to the inside of a length of SS316 stainless steel tubing. This tubing is $42 \mathrm{~mm}$ in diameter with an internal diameter of $22.5 \mathrm{~mm}$, prior to machining. The oil shale is a $25 \mathrm{~mm}$ diameter cylinder. The total length of the oil shale holder and oil shale core is $37 \mathrm{~mm}$.

The average thickness of each flange is $14.7 \mathrm{~mm}$ thick. Each flange is $128 \mathrm{~mm}$ in diameter. The bolt holes are centered $16.5 \mathrm{~mm}$ from the flange edge.

Figures 8-10 show the individual flanges in detail. Each Figure shows a cross-section of the flange at the bottom, and above shows a side view of that flange. Figure 9 is little confusing, because both sides of the flange are shown together, as if the flange were made of a transparent material.

\footnotetext{
${ }^{1}$ It was later discovered that silicon rubber was unsuitable for the reactor conditions. While silicon rubber is stable to over $670 \mathrm{~K}$, it is not resistant to $\mathrm{HCl}$ gas.
} 


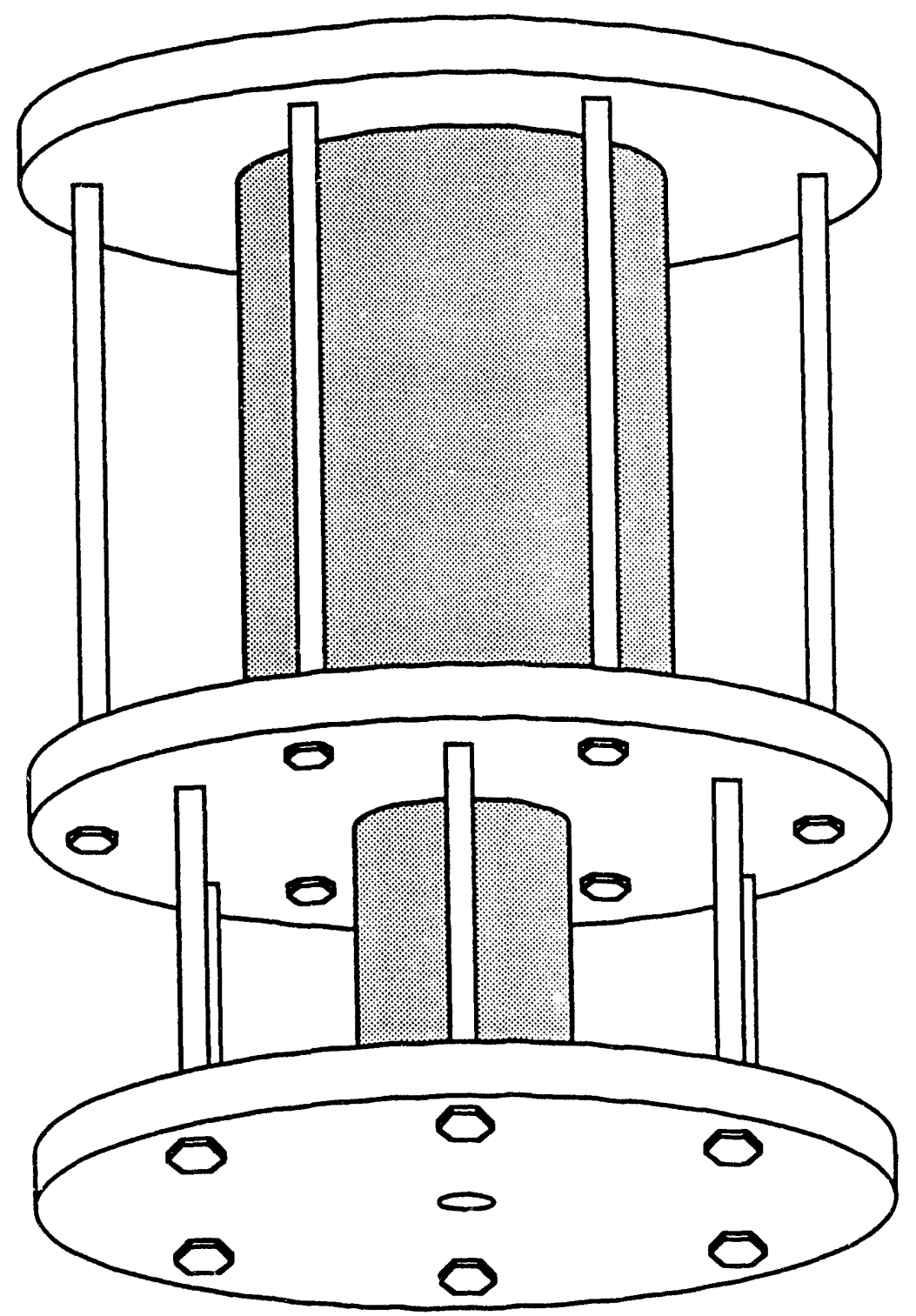

Figure 6. Perspective View of Assembled Reactor. 


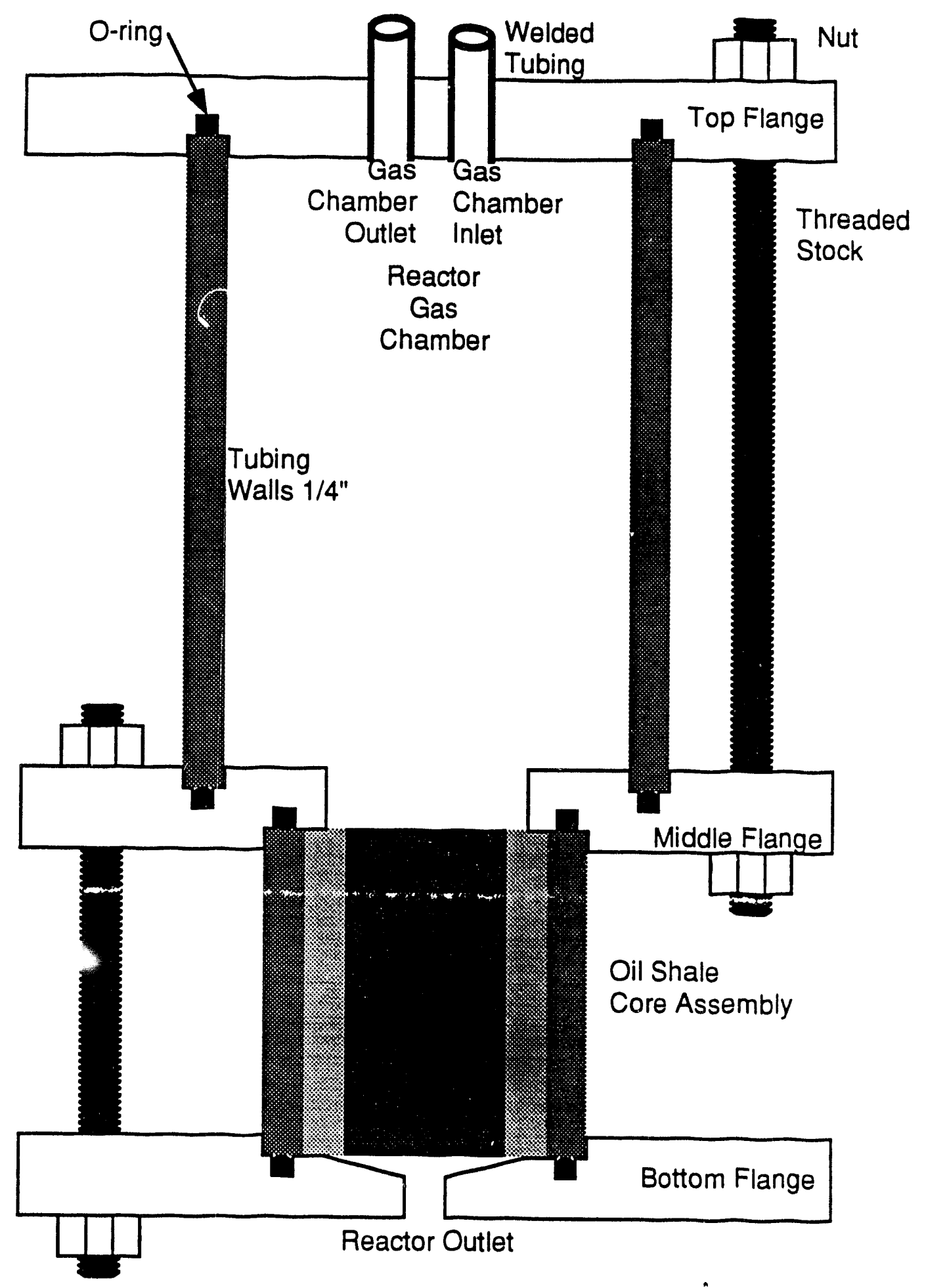

Figure 7. Cross Section View of Assembled Reactor. 


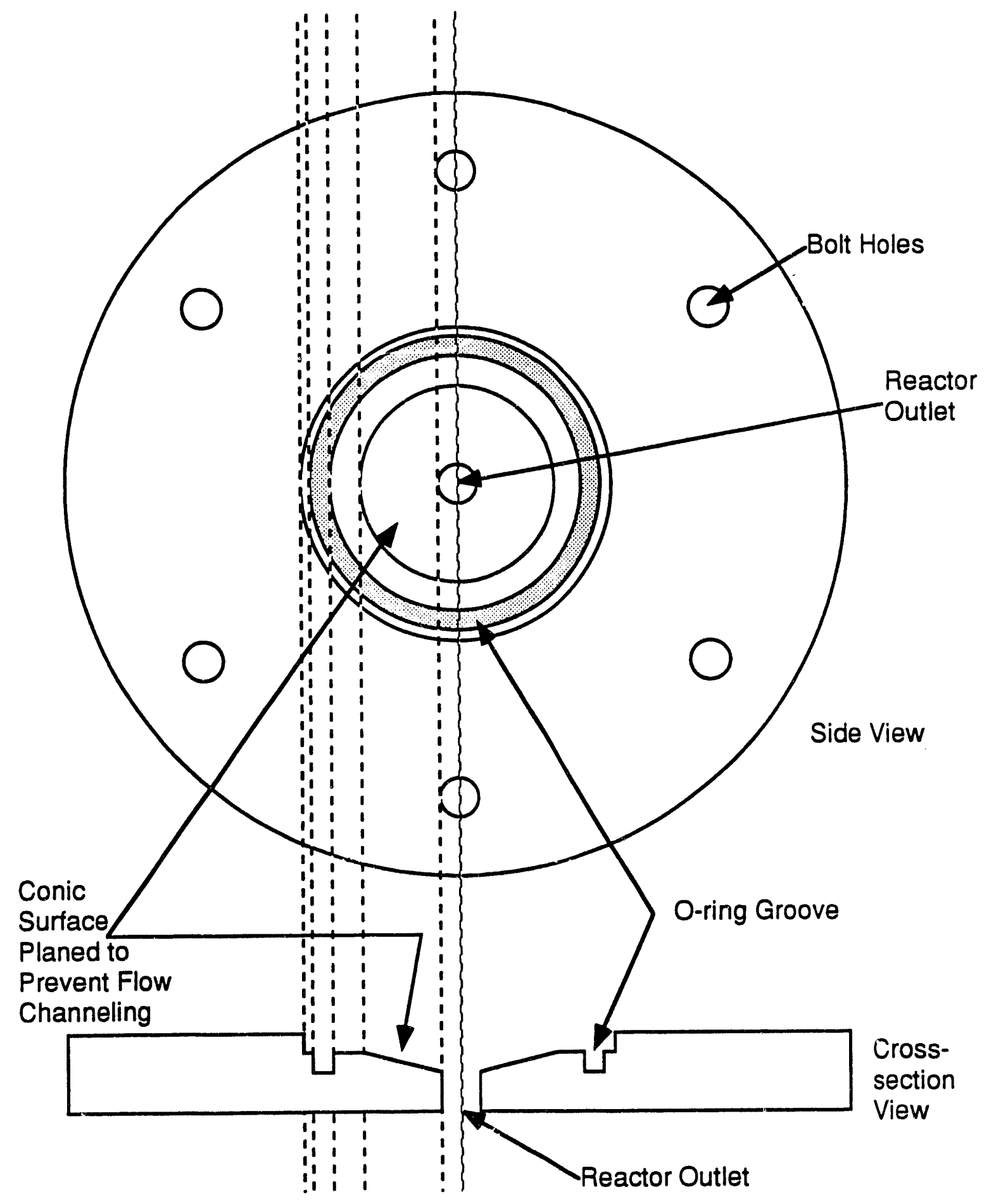

Figure 8. Bottom Flange of Reactor. 


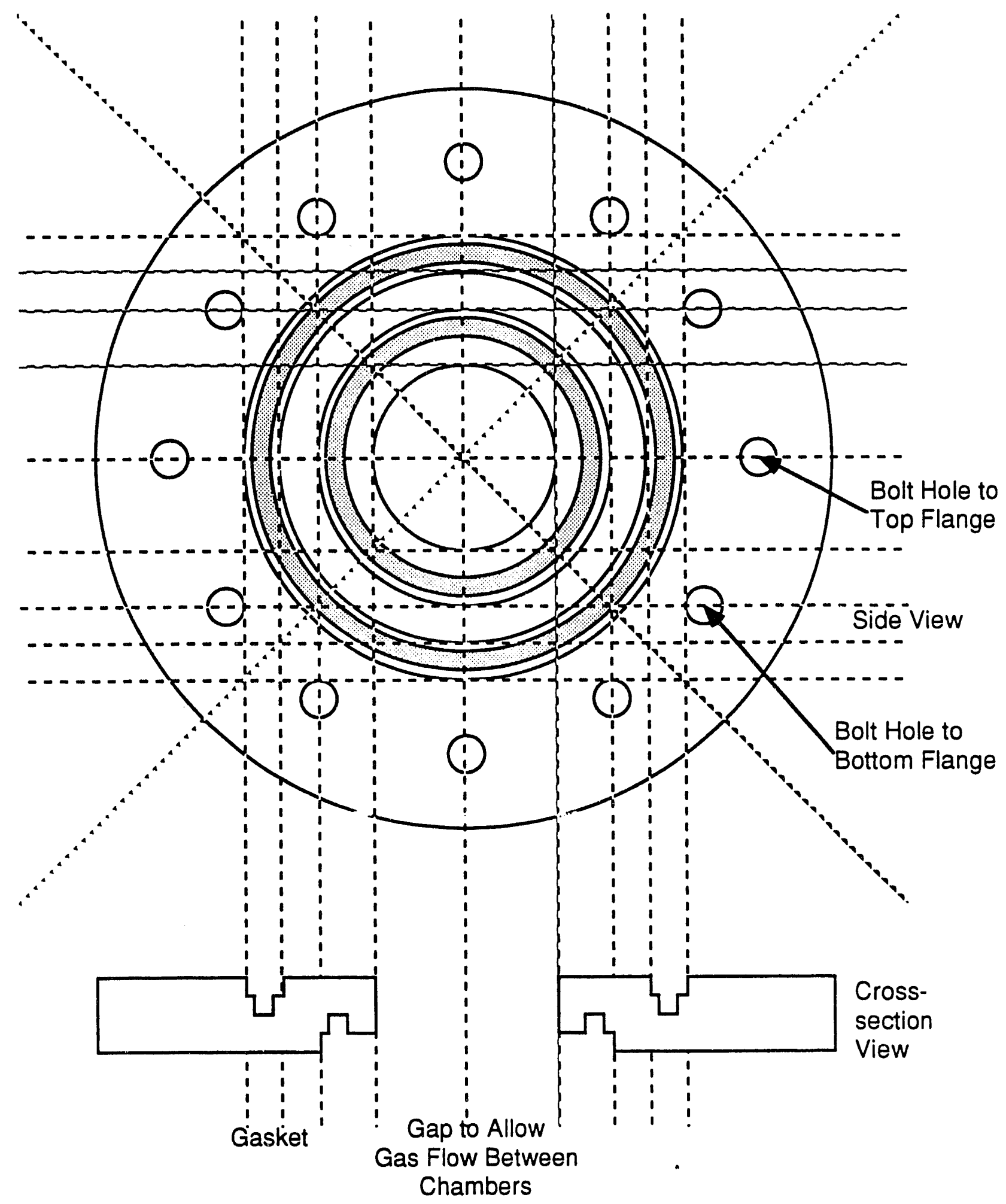

Figure 9. Middle Flange of Reactor. 


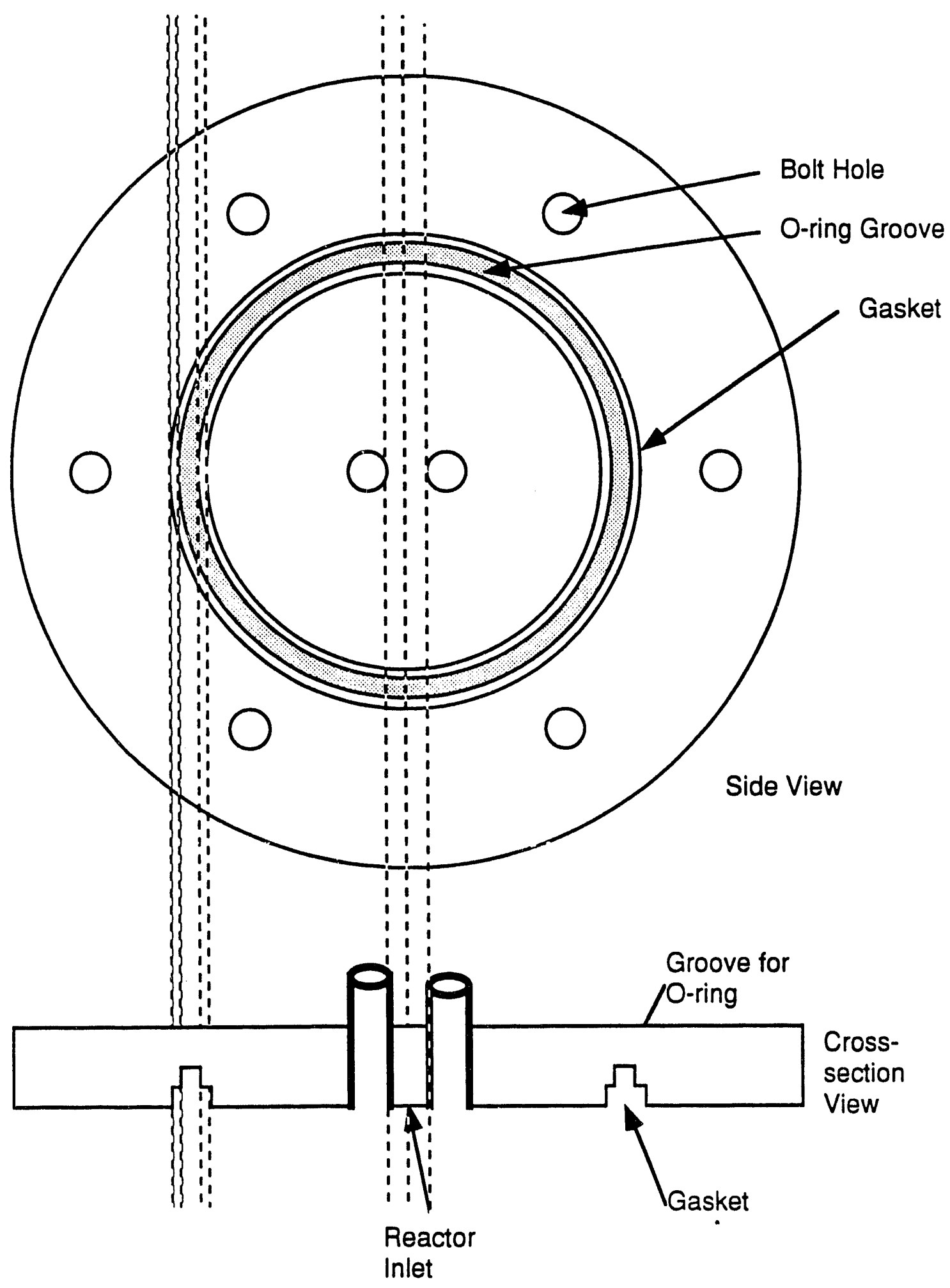

Figure 10. Top Flange of Reactor. 
The first chamber contained the oil shale core. The cylindrical shale core was sealed to the chamber tubing with a high-temperature-lowviscosity epoxy. Because the process of sealing the core to the stainless steel tubing covered both core faces, it was found to be necessary to remove the epoxy by turning the assembly on a lathe, machining both faces.

The second chamber served as a gas mixing chamber where thermal convection would prevent the formation of gas phase concentration gradients and reactant depletion near the core face. This maintained a high concentration gradient just within the oil shale, giving a high reactant flux into the core. The reactor temperature was maintained by immersing the entire reactor assembly into a hot fluidized sand bath. The sand was heated by electric heating elements, and the well-mixed property of the fluidized bed ensured that the temperature within the bath was uniform. A perspective drawing (Figure 6) and a cross-section drawing (Figure 7) of the reactor are included.

The reactor core holder has been modified. (See Figure 11.) The previous design for the core holder had approximately a $0.5 \mathrm{~cm}$ annulus between the pipe and the core. The new design's annulus is $0.5 \mathrm{~mm}$. The smaller annulus reduced the surface area available for chemical attack, required much less adhesive than previously, and reduced the amount of binder available for reaction with the reactant gases, decreasing the amount of reactant gases lost 1 . More importantly, the reduced amount of adhesive will decrease the effect of the thermal expansion of the epoxy compressing the oil shale. Epoxies generally have a linear thermal expansion coefficient of about $6 \cdot 10^{-5}{ }^{\circ} \mathrm{C}^{-1}$, six times greater than that of stainless steel, $10^{-5}{ }^{\circ} \mathrm{C}^{-1}$. It had been noticed that prior to heating the reactor, there was significant flow through the apparently intact core, even at small pressure drops. However, after heating the reactor to reaction temperature, this communication was lost entirely. The closing off' of the core was attributed to the high thermal expansion coefficient of the epoxy. The most important result is that the thin annulus allowed the use of a new adhesive with special curing requirements. (See the Reactor Design Section.)

A comprehensive examination of available adhesive materials has been conducted. Two venders were involved, Cotronics Corporation (Brooklyn, NY) and Sauereisen Cement Company (Pittsburgh, PA). Because of the high temperatures required for the reaction, it was originally determined that the only polymeric materials with sufficiently high temperature ratings were (in general) epoxies and silicon rubbers.

A number of flowable epoxies were selected for binding the core to the pipe, and silicone rubber o-rings were used to seal the pipe to the reactor. Unfortunately, the epoxies were selected based on a (presumed)

\footnotetext{
${ }^{1}$ Previous experiments revealed that the lower temperature epoxies were significantly degraded by chemical reaction.
} 
requirement of low viscosity; these epoxies were attacked by the $\mathrm{HCl}$, as were the o-rings. (See the Experiments Section.)

Because of the chemical reactivity of silicon rubber and the flowable epoxies, non-organic-based adhesives were then examined. Ceramic materials are well known for their high temperature limits, but their thermal expansion coefficients are generally lower than that of stainless steel. This could result in the separation of the ceramic binder from the inside of the stainless steel pipe, breaching the seal.

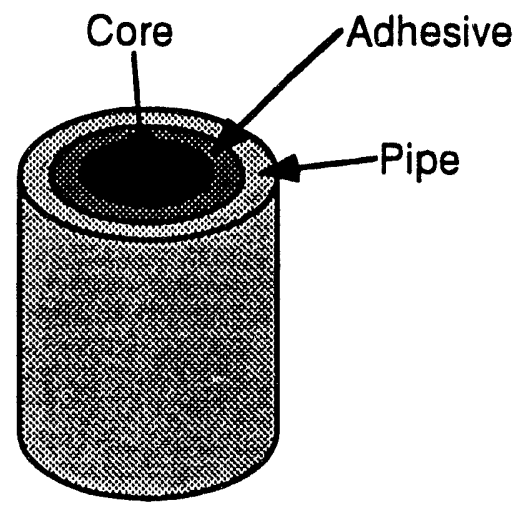

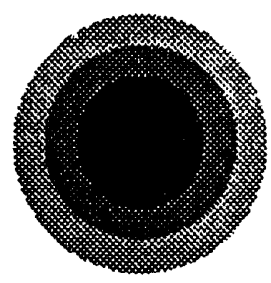

Old Design

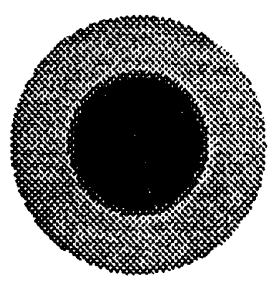

Thin Annulus

Figure 11. Core Holder Modification Detail

Both Cotronics and Sauereisen market ceramic based materials. Additionally Cotronics markets metallic based materials. One of their stainless steel based adhesives and their aluminum based adhesive both have a linear thermal expansion coefficient equal to that of stainless steel. Unfortunately, all of the ceranic and metallic adhesives tested failed to form a vacuum-proof seal. Both venders confirmed that the inorganic cements are unsuitable for forming vacuum-proof seals.

Based on the work with the paste-like ceramic and metallic adhesives, it was discovered that a flowable adhesive was not necessary. A paste epoxy, requiring extensive curing, was purchased from Cotronics and is rated to withstand $370^{\circ} \mathrm{C}, 50^{\circ} \mathrm{C}$ higher than the reaction temperature.

From a local vendor, two more promising materials were found: a hightemperature (to $400^{\circ} \mathrm{C}$ ) silicone rubber sealing compound and a graphitebased high temperature (to over $550^{\circ} \mathrm{C}$ ) repair adhesive (e.g., for outdoor charcoal grills). Unfortunately, both adhesives cure via the release of a simple molecule: acetic acid and water, respectively. With the original design of the core holder, and the sealing properties of both adhesives, neither would cure beyond a depth of a few millimeters (core total length approximately $3 \mathrm{~cm}$ ) within a week, because the adhesive surface quickly formed an impermeable skin. It had been noted that oil shale had a (limited) capacity to absorb water into its minute fissures. Thus it was conjectured that the water released from the curing of a very thin film of the graphite adhesive could possibly be absorbed by the oil shale. By experimentation, it was found that a $0.5 \mathrm{~mm}$ annulus was sufficiently thin 
to permit complete curing. The silicone rubber has been abandoned from use as a core holder binder fur two reasons: 1 ) due to the release of acetic acid, which might result in a non-negligible and non-measurable recovery process, and 2) the previously noted chemical instability of silicon rubber.

The resistance of the graphite based adhesive to chemical attack was still unknown. Specifically, it was unknown whether or not the material will react at $325^{\circ} \mathrm{C}$ with $\mathrm{HCl}$ (forming $\mathrm{CH}_{i} \mathrm{Cl}_{4-i}, \mathrm{i} \in[0,4]$ ), with $\mathrm{H}_{2} \mathrm{O}$ (forming $\mathrm{CO}$ and $\mathrm{H}_{2}$ ), or with $\mathrm{CO}_{2}$ (forming $\mathrm{CO}$ ). The material was never tested, because the paste epoxy was found to be chemically stable.

During the preliminary experiments, it was noticed that the silicone rubber 0-rings were failing. Above $260^{\circ} \mathrm{C}$ with $\mathrm{HCl}$, the rubber was losing its elasticity, becoming a paste. When the temperature was increased to $288^{\circ} \mathrm{C}$, the rubber began to change from red to an ashen grey. At this point, a search for an alternative o-ring material was begun. When it was discovered that metal o-rings could be manufactured, an order was made. The reactor flanges' o-ring grooves are being re-machined to provide a shallower groove for the metal o-rings. This will improve the seals.

The modifications to the original process were completed when the metal o-rings arrived. The gasket grooves for the silicon rubber o-rings had to be remachined to accommodate the metal o-rings. The process then was capable of running the reaction at the optimal conditions: $325^{\circ} \mathrm{C}$ and 6 bar. 


\section{LITERATURE}

The literature publications that had the greatest impact upon this research project are listed below.

An initial literature search was informative. Recent work with kerogen revealed by the use of controlled pyrolysis that the structure of kerogen is a highly three-dimensionally cross-linked carbon polymer [4,5]. It has been suggested that ozone, $\mathrm{O}_{3}$, may be useful for freeing the kerogen by controlled oxidation of the cross-linkages [6]. The reactor design would be ideal for such experiments, which may be useful to differentiate between various reaction/recovery mechanisms.

A later literature search revealed that the pyrolysis reactions for modified in situ retorts (which are the most relevant to the chemically assisted in situ recovery method) are rate limited, instead of mass transport limited [7]. It is uncertain at this time whether the chemically assisted in situ method is mass transfer or kinetic limited. 


\section{EXPERIMENTS}

The experiments are summarized in Table 1 . The first experiments were intended to shake the bugs out of the experiment equipment and experiment design. Surprisingly, the first experiment yielded free oil. Later experiments were not so successful, yet were probably more useful in terms of knowledge gained.

Early problems encountered included epoxy degradation, silicon degradation, corrosion, freed oil losses due to poor equipment design, thermocouple failure (and ignition during one experiment), pressure transducer corrosion failure, freed oil losses due to transport to isolated equipment (specifically, the PTs), and plugged tubing (due to freezing of organics).

Some notes about Table 1. In Experiment \#6, an Inconel sheathed thermocouple corrosion failed. The contents of the thermocouple ignited in the reactive atmosphere of the reactor, with temperatures exceeding $1600 \mathrm{~K}$.

In Experiment \#7, the breakthrough time was not observed because the exit tube from the reactor was discovered to be clogged with sand and frozen organic material.

Experiment \#8 was interrupted by a period of nearly a week, during which the reactor was kept at room temperature.

The first chemical flood was run during Experiment \#9 when partial breakthrough occurred at 6 hours. The breakthrough was minimal, and allowed such a slow flow of reactant gas that the reactor was emptied approximately once an hour.

The steady state gas mixer was installed prior to Experiment \#10. Thus the chemical flood process was controlled.

The first three experiments were run at temperatures below the optimum. The first experiment ran for six and a half hours at $250^{\circ} \mathrm{C}$ with $10 \% \mathrm{HCl}$ and $90 \% \mathrm{H}_{2} \mathrm{O}$ at $6 \mathrm{bar}$, and produced less than $10 \%$ recovery of shale oil. We could not operate at the optimal temperature because of temperature limitation of the epoxy. Even though the temperature was within the limits of the epoxy, it failed so completely that the core fell out of the core holder down into the gas chamber. Thus breakthrough was not achieved. Approximately $0.3 \mathrm{~mL}$ of shale oil was recovered.

The second experiment ran eight hours at $255^{\circ} \mathrm{C}$ with $<1 \% \mathrm{HCl}$, but produced no shale oil. A new epoxy withstood the reactor conditions nearly untouched. The reactor for this run had been turned up-side down to prevent the core holder failure seen in the first experiment. 
The third experiment ran over 26 hours at $260{ }^{\circ} \mathrm{C}$ with $18 \% \mathrm{HCl}, 10 \%$ $\mathrm{CO}_{2}$, and $72 \% \mathrm{H}_{2} \mathrm{O}$ at 15 bar. Breakthrough was not obtained; thus a huffand-puff strategy was employed for three cycles. Solids were sucked out of the reactor (apparently epoxy fragments). The face of the core exposed to the gas chamber was torn to pieces and had undergone significant volume expansion. The appearance of the core was quite oily, though no free oil was obtained. The epoxy exposed to the gases was also badly weathered, for the most part intact, but no longer bonding the core (due to the volume expansion). The epoxy-core bonding on the other side of the core was intact.

\begin{tabular}{|c|c|c|c|c|c|c|}
\hline \# & $\mathrm{T}(\mathrm{K})$ & $\begin{array}{l}\text { Total } \\
\text { hours }\end{array}$ & $\begin{array}{l}\text { Break- } \\
\text { thru } \\
@ \\
\text { Hour }\end{array}$ & $\begin{array}{l}\text { Refill } \\
\text { each } \\
X \\
\text { hours }\end{array}$ & $\begin{array}{l}\mathrm{HCl} \\
\text { partial } \\
\mathrm{P} \\
(\mathrm{kPa})\end{array}$ & Comments \\
\hline$T$ & 505 & 11 & no & 2.8 & 55 & $0.5 \mathrm{~mL}$ free oil' (12\%); epoxy "melted" \\
\hline 2 & 533 & 10 & no & 1.8 & 135 & epoxy eaten \\
\hline$\overline{3}$ & 533 & 27 & no & 6.5 & 172 & epoxy eaten \\
\hline 4 & 550 & 11 & no & 1.5 & 127 & \\
\hline 5 & 600 & 63 & $\overline{53}$ & 3.5 & 124 & $\begin{array}{l}2 \text { TCs failed/replaced; } \\
\text { simultaneous union corrosion failure \& core } \\
\text { break-through; free oil }{ }^{2}\end{array}$ \\
\hline 6 & 600 & 62 & $\overline{53}$ & 2.9 & 137 & $\begin{array}{c}\text { TC failed; } \\
\text { tube corrosion failure }\end{array}$ \\
\hline 7 & 600 & 112 & $\begin{array}{c}\text { yes, } \\
\text { hidden }\end{array}$ & 2.7 & 140 & $\begin{array}{l}\text { tube corroded through: repaired \& resumed; } \\
\text { halt due to valve failure; } \\
\text { tube clogged by sand; }\end{array}$ \\
\hline 8 & $\overline{600}$ & 758 & $\begin{array}{l}13 \\
30 \\
707\end{array}$ & $\begin{array}{l}4.5 \\
3.7 / 8 \\
.4\end{array}$ & 118 & sand \& oil clogging \\
\hline 9 & 500 & 83 & (6) 9 & 7.9 & 92 & $\begin{array}{l}\text { 1st chemical flood; free nil; } \\
\text { dry organic in cyclone; } \\
\text { 2 PTs corrosion failed; } \\
\text { 2 TCs plugs melted }\end{array}$ \\
\hline 10 & 600 & $\begin{array}{l}72+ \\
1.5+ \\
26\end{array}$ & 31 & $\begin{array}{l}8.0 \\
6.6\end{array}$ & & $\begin{array}{c}\text { Ist controlled cinemical flood; } \\
\left.3.0 \mathrm{~g} \text { organic recovered (Recovery }=90 \%{ }^{3}\right) \\
\text { PT diaphragms leaked; } \\
\text { tubing plugged }\end{array}$ \\
\hline
\end{tabular}

Table 1. Summary of Experiments.

1 Visual Estimate of Volume.

2 Not enough shale oil was recovered to measure. Presence of free shale oil was confirmed by smell and observation of oil film on recovered waste water.

${ }^{3}$ Assumes density of organic material of $\rho=0.8$ and shale oil yield of 30 gal ton ${ }^{-1}$. 
Reaction \#5 was run for 53 hours before breakthrough occurred. Breakthrough was indicated by a sharp pressure rise on the down-streamside of the core, which was open to a 1.5 Liter collection vessel. Unfortunately coincident to breakthrough was the total failure of a Swagelok-to-Cajun-VCR adaptor union, forcing immediate shutdown before any enhanced oil recovery technique could be attempted. In spite of this, a small amount of oil was observed in the tubing on the core side of the reactor (which is physically beneath the core). The failure of the union cut short the experiment by about 40 hours. After breakthrough, it was planned that the reactant gases would be flowed through the core for approximately 24 hours, followed by approximately 24 hours of steam flooding that would force the freed oil out of the core matrix.

Once the mass flow controller was finally functional, an experiment was begun. The core was initially non-permeable-the chemical soak procedure was used first. Intermittent break-through occurred very early, probably due to the presence of large cracks visible on the rear face of the core. (The cracks were not visible on the front face; thus there was no initial permeability.) When conclusive communication through the core was observed, the steady state gas flow procedure ("chemical flood") was initiated. The chemical flood proceeded for two hours, until clogging problems forced use to shutdown.

During clean-up, a fitting was found completely sealed with a waxy organic material that was very soluble in tetrahydrofuran (THF). The fitting was located in a section that was not heated due to a non-functional temperature controller. (The temperature controller was calibrated for a type $J$ thermocouple, but a type $\mathrm{K}$ thermocouple had been used.)

The experiment might have been continued after the clog had been removed, except that the nitrile rubber diaphragms used to chemically isolate the pressure transducers from the corrosive reactant gas mixture began to leak. The leak allowed material to flow into the small chamber between the diaphragm and the pressure transducer. This chamber (which was filled with mineral oil) acquired a positive pressure and invalidated the calibration. Without accurate pressure measurement, it was impossible to accurately load the gas chamber. Viton replacements ware purchased.

The processes recovery efficiency has not been computed yet, because of separation difficulties. The organic material collected was mixed with water, which also contained nickel and chromium salts. The organic material is most soluble in THF, but using THF solvent extraction resulted in a colloidal mess.

By solvent extraction and washing, $3.0 \mathrm{~g}$ of organic material was recovered from the experiment (some material was lost due to spillage and is not included in the total $3.0 \mathrm{~g}$ ). Assuming the organic material has a density of 0.8 and the raw oil shale (which is about 30 gallons shale oil per ton of rock) contains $20 \%$ organic material by volume, the $3.0 \mathrm{~g}$ organic material translates into a recovery of $97 \%$. The organic material is 
extremely soluble in methylethylketone (MEK) and tetrahydrofuran (THF), but only slightly soluble in cyclohexane. The organic material is solid at room temperature, but is apparently highly volatile at $600 \mathrm{~K}$ (by its presence in remote locations, such as the pressure transducers).

It should be noted that THF is an unsuitable solvent for liquid-liquid extraction from the collected aqueous phase. THF reacts with the $\mathrm{HCl}$ in the collected aqueous+acid+organic mixture.

$$
\mathrm{THF}+\mathrm{HCl}_{\text {aqueous }} \rightarrow \mathrm{ClH}_{2} \mathrm{CCH}_{2} \mathrm{CH}_{2} \mathrm{CH}_{2} \mathrm{OH}
$$

Rxn 6. 


\section{INSTRUMENTATION}

A number instrumentation purchases were made. We already had a gas chromatograph and a number of thermocouples from previous research projects. We needed a number of pressure transducers, a computer, data acquisition hardware, and a gas chromatography column suitable for analyzing mixtures of $\mathrm{HCl}, \mathrm{CO}_{2}, \mathrm{H}_{2} \mathrm{O}$, and light hydrocarbons.

A gas chromatograph column suitable for analyzing mixtures of $\mathrm{HCl}$, $\mathrm{CO}_{2}, \mathrm{H}_{2} \mathrm{O}$, and light hydrocarbons was purchased. The column originally installed in the GC was suitable for heavier hydrocarbons and preliminary tests indicated that it cannot separate the gases. We installed the second column parallel to the first so that lengthy change-overs would not be required to analyze both the light gases and the freed shale oil. The only caveat was the new column had an upper temperature limit near the ideal oven temperature for the other column.

Then, two major purchases remained. A data acquisition processing (DAP) board was selected. The features of the DAP included the usual hardware present on a data acquisition board, a powerful CPU, an on-board real-time operating system, and many useful subroutines stored in the onboard ROM. This DAP was selected because it would allow rapid set-up of the data acquisition system (because little or no software need be written) and would leave the computer's own CPU free to perform Kalman filtering, parameter estimation, and modelling in real time without the additional burden of acquiring and processing data.

The Data Acquisition Processing (DAP) board, purchased from Microstar Laboratories, arrived and was installed. Because the DAP board has its own CPU, real-time operating system, and many on-board,ROMbased commands, set-up was extremely quick and easy. The DAP board performed very well.

There are only two deficiencies with the data logging and plotting software that was included with the DAP board purchase. First, plotted data that has scrolled off the computer screen can not be recovered and reviewed. Second, the program's disk logging function has no averaging capability. The later is a serious problem because of the amount of data generated during one experiment. Experiment \#5, which ran for 53 hours yet was cut short by at least 48 hours, generated over 5 Megabytes of data with the DAP board providing data averaged over 3 seconds. The DAP board can be programmed to average data over any time period, but it is necessary to be able to observe the process data at least every five seconds.

Furthermore, computation of the amounts of gases flowed into the reactor gas chamber requires that the pressures be available (on disk) every second.

One possibility was to average the data over a period of time in which the data were relatively constant. When the data changed significantly, it was saved to disk along with the current time. 
In order to identify the various parameters for the simulation model, it is necessary to know the gas concentrations within the gas chamber and exiting the reactor in real-time. Thus, an on-line instrument is necessary to measure the concentrations of $\mathrm{HCl}$ and of $\mathrm{H}_{2} \mathrm{O}$ or $\mathrm{CO}_{2}$ on-line (the third may be estimated with an Equation of State (EOS) by assuming there are no other gases present). The first choice of instruments, gas chromatography, is not feasible. The design is based on gas-phase-absorption-near-infrared (IR) spectroscopy.

While a gas chromatograph would theoretically perform as required, in practice the damage caused to the thermal conductivity detector's (TCD) filaments by acid etching would be problematic and expensive at best. A TCD is necessary because the more commonly used flame-ionization detector (FID) is incapable of detecting either $\mathrm{H}_{2} \mathrm{O}$ or $\mathrm{CO}_{2}$. To further complicate matters, any chemical means of striping out $\mathrm{HCl}$ would also strip out $\mathrm{H}_{2} \mathrm{O}$ and $\mathrm{CO}_{2}$.

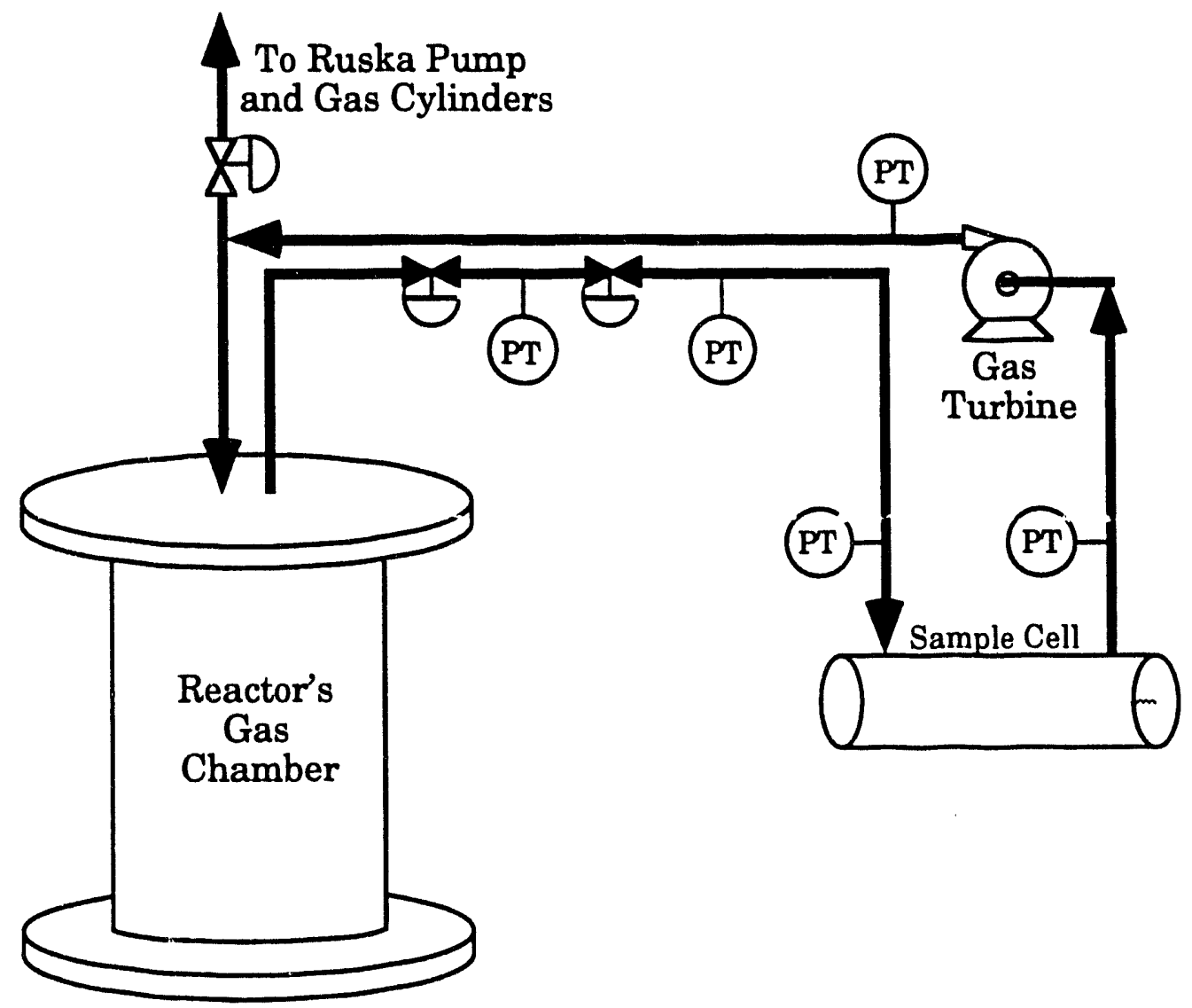

Figure 12. Sample Loop Diagram.

The infrared spectroscopy method has been used to measure $\mathrm{HCl}$ concentrations to several parts per million $[8,9]$ with a $100 \mathrm{~mm}$ optical path. All three gases have distinctive infrared absorptions. However, infrared sources and optics are expensive, and difficult to use. Fortunately, 
quantum effects allow the use of harmonic overtones of the specific infrared frequencies that are in the near-infrared domain. Near-infrared diode lasers are cheap, easy to control, and reliable and ordinary optics may be used. Figures 12-14 show the near-IR spectrometer design.

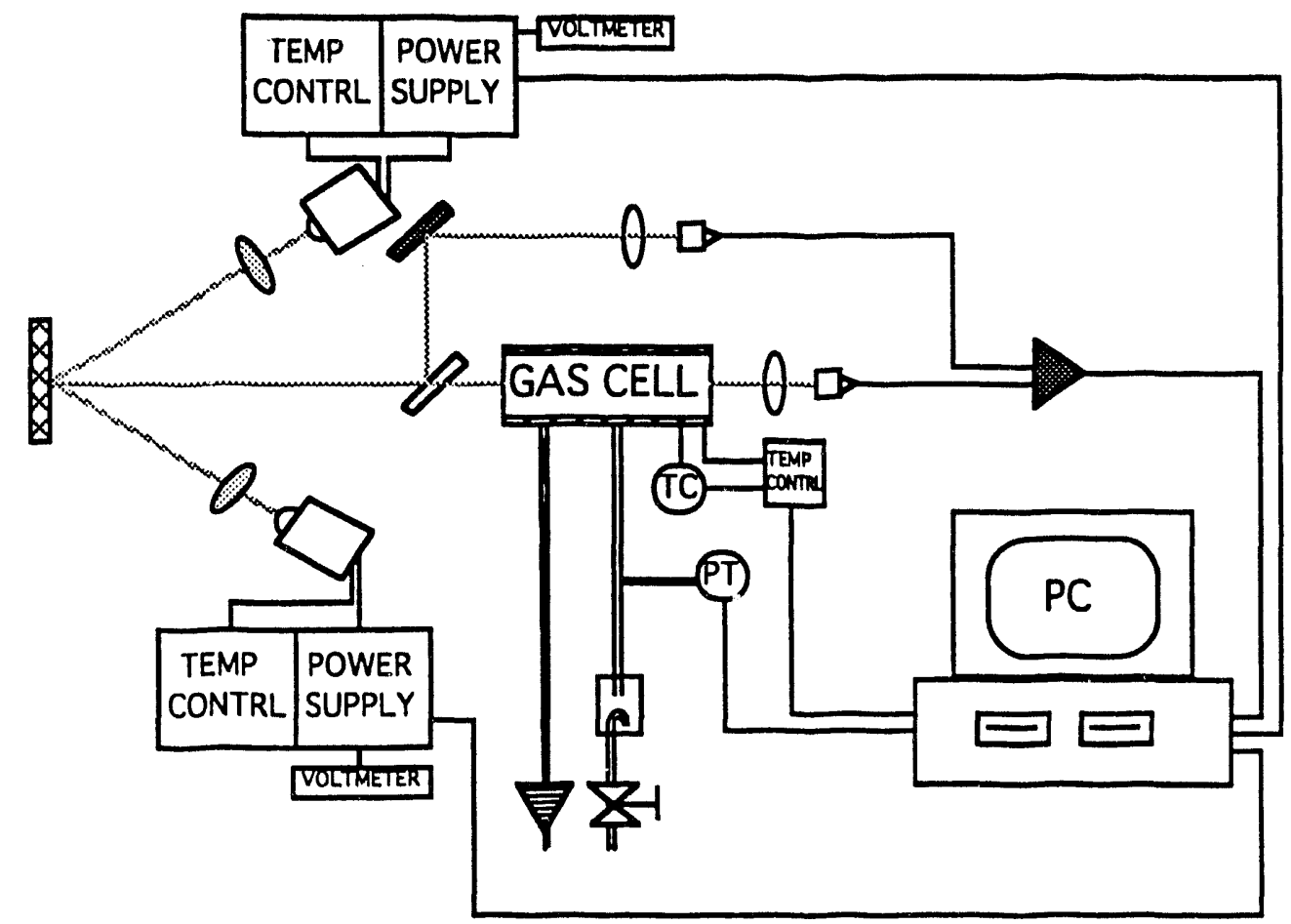

Figure 13. Design of near-IR Spectroscope.
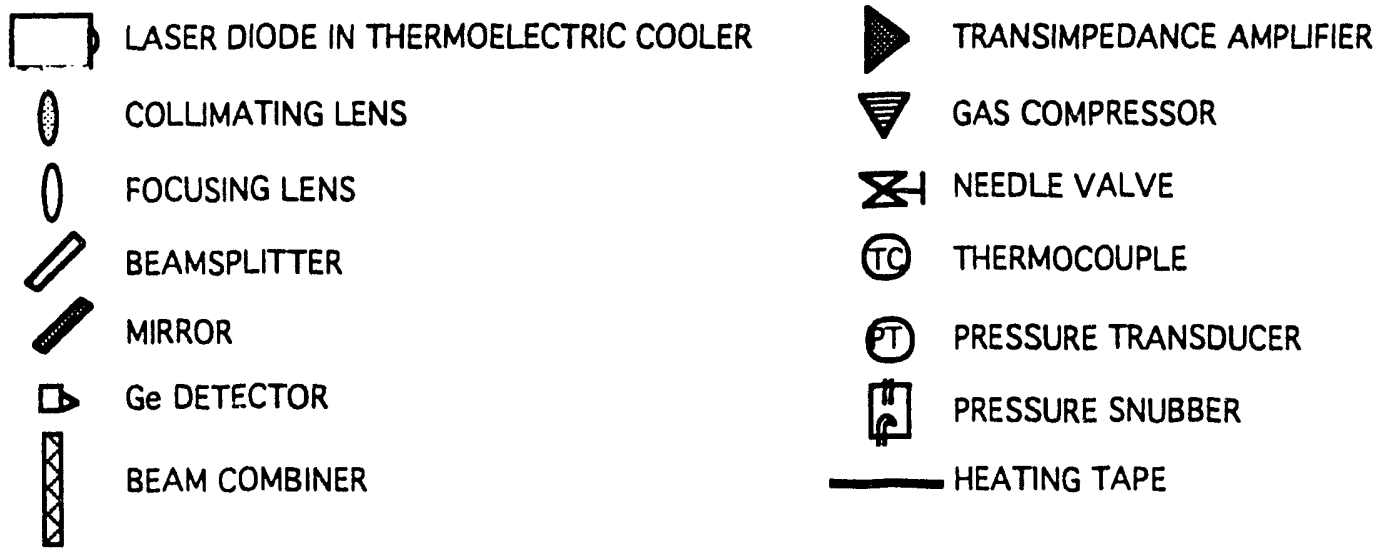

Figure 14. Key to Figure 13.

The data acquisition program was completed (with the use of the beta release of the OS/2 device driver for the DAP). The program acquired data, then averaged and filtered the data. The program also saved the data to the computer's disk while plotting the data on screen. The unusual feature of the data acquisition program was that the program ran under the OS/2 operating system for IBM-PC compatible personal computers. The program 
ran under the Presentation Manager windowing system, allowing the computer to be used for other tasks while monitoring the experiment. It was planned that computationally intensive tasks, such as compiling and running advancing simulations, would be performed while experiments were run. This would allow the computer to run on-line parameter identifications without losing transient data.

The on-line near infrared spectrometer was never constructed due to insufficient funding.

The manufacturer of the data acquisition processor (DAP) hardware finally released the first version of the DAP device driver for OS/2. It was then discovered that the new version of the device driver required that the data acquisition software be updated and recompiled to be used with the new device driver. Unfortunately, the software library supplied with the new device driver could not be used with the compiler we had. After several months, the exact cause of the trouble was finally diagnosed. The manufacturer was contacted and a solution was devised. The data acquisition software was updated and recompiled to take advantage of the new device driver.

The above problem was that the IBM C Set/2 compiler has undergone significant alterations between the version possessed by the researchers and the version required by the software library. Specifically, the software library required a certain compiler function, which had been (slightly) renamed when the compiler was updated. Recompiling the software library for use with the new version of the compiler (after the manufacturer supplied the source code) fixed the function name mismatch. The base of the data acquisition program is now functional. The strip-chart style plotting routine of the data acquisition program is nearly functional.

Communication with Hewlett-Packard (HP) revealed that the thermal conductivity detector (TCD) installed in the gas chromatograph (GC) has platinum filaments, not tungsten filaments. Furthermore, a HP chemist asserted that the platinum filaments should resist any corrosion from the $\mathrm{HCl}$ present in the gas samples. Thus the GC with the TCD would suffice to monitor the gas concentrations within the gas chamber and in the exit stream. The near-infrared spectrometer previously designed and presented is thus unnecessary. Professor John Falconer of the Department of Chemical Engineering at the University of Colorado-Boulder confirmed this. Professor Falconer was not able to confirm the corrosion resistance of platinum filaments in face of higher concentrations (percents of $\mathrm{HCl}$, which is what we used). 


\section{MODELLING AND SIMULATION}

\section{DIFFUSION-LIMITED, INFINITE GAS CHAMBER, HOMOGENEOUS SOLID BREAKTHROUGH MODET}

A first approximation model for linear diffusion and reaction with a sharp reaction front was constructed. The diffusion-limited, homogeneous breakthrough model assumes fast reactions limited by the component diffusions. The reactants diffuse through the reacted shale core to the sharp reaction front. The concentration of $\mathrm{HCl}$ and $\mathrm{H}_{2} \mathrm{O}$ are zero at the reaction front while the $\mathrm{CO}_{2}$ is formed from the two desired reaction. The competing reaction, de-carbonation of the dolomite forming dichloride salt, is at equilibrium. Finally, the reaction front movement rate is proportional to the rate of consumption of the concentration of the binding sites within the shale.

The model previously discussed was solved numerically, and compared with the convenient pseudo-steady state solution. The resulting dimensionless equations follow: $x_{i}$ is component mole fraction in shale core, $\tau$ is dimensionless diffusion time (based on the effective diffusion of $\mathrm{HCl}$ through the solid matrix), $\zeta$ is dimensionless length from origin of diffusing reactants, $D_{i}$ is component diffusivity, $\lambda$ is the dimensionless location of the reaction front, and $C_{n}$ is the molar concentration of component $\mathrm{n}$ within the core.

$$
\begin{aligned}
& \frac{\partial \mathrm{x}_{\mathrm{HCl}}}{\partial \tau}=\frac{\partial^{2} \mathrm{x}_{\mathrm{HCl}}}{\partial \zeta^{2}} \\
& \frac{\partial x_{\mathrm{H}_{2} \mathrm{O}}}{\partial \tau}=\left[\frac{\mathrm{D}_{\mathrm{H}_{2} \mathrm{O}}}{D_{\mathrm{HCl}}}\right] \frac{\partial^{2} \mathrm{x}_{\mathrm{H}_{2} \mathrm{O}}}{\partial \zeta^{2}} \\
& \frac{\partial \mathrm{x}_{\mathrm{CO}_{2}}}{\partial \tau}=\left[\frac{\mathrm{D}_{\mathrm{CO}_{2}}}{\mathrm{D}_{\mathrm{HCl}}}\right] \frac{\partial^{2} \mathrm{x}_{\mathrm{CO}_{2}}}{\partial \zeta^{2}} \\
& \left.\frac{\mathrm{d} \lambda}{\mathrm{d} \tau}=\frac{\mathrm{C}_{\text {shale }}}{\mathrm{C}_{\mathrm{Rxn} \text { Sites }}}\left(\frac{\partial \mathrm{x}_{\mathrm{HCl}}}{\partial \zeta}\right]_{\zeta=\lambda}+\left.2\left[\frac{\mathrm{D}_{\mathrm{H}_{2} \mathrm{O}}}{\mathrm{D}_{\mathrm{HCl}}}\right] \frac{\partial \mathrm{x}_{\mathrm{H}_{2} \mathrm{O}}}{\partial \zeta}\right|_{\zeta=\lambda}\right)
\end{aligned}
$$

The dimensionless variable definitions follow.

$$
\tau \equiv\left(\frac{\mathrm{D}_{\mathrm{HCC}} \mathrm{t}}{\mathrm{L}^{2}}\right) ; \quad \zeta \equiv\left(\frac{\mathrm{z}}{\mathrm{L}}\right) ; \mathrm{x}_{\mathrm{i}} \equiv\left(\frac{\mathrm{C}_{\mathrm{i}}}{\mathrm{C}_{\text {shale }}}\right) ; \lambda \equiv\left(\frac{1}{\mathrm{~L}}\right)
$$

The initial and boundary conditions follow. 


$$
\begin{aligned}
& @ \zeta=\lambda: x_{\mathrm{HCl}}=\mathrm{x}_{\mathrm{H}_{2} \mathrm{O}}=0 \text { and } \\
& \left.\frac{\partial \mathrm{x}_{\mathrm{CO}}}{\partial \zeta}\right|_{\zeta=\lambda}=-\left(\left.\left[\frac{\mathrm{D}_{\mathrm{HCl}}}{\mathrm{D}_{\mathrm{CO}}}\right] \frac{\partial \mathrm{x}_{\mathrm{HCl}}}{\partial \zeta}\right|_{\zeta=\lambda}+\left.2\left[\frac{\mathrm{D}_{\mathrm{H}_{2} \mathrm{O}}}{\mathrm{D}_{\mathrm{CO}_{2}}}\right] \frac{\partial \mathrm{x}_{\mathrm{H}_{2} \mathrm{O}}}{\partial \zeta}\right|_{\zeta=\lambda}\right)
\end{aligned}
$$

Eqn 8.

The model is a moving boundary diffusion system and is difficult to solve numerically. An analytical solution (via a similarity variable) was thought to be possible, but was never attempted. Thus the focus was on obtaining a numerical solution that would allow the inclusion of more realistic assumptions with minimal additional effort. The Crank-Nicolson finite difference method is currently the method of choice-the difficulty arises from the moving boundary. One idea was to quantize the boundary's movement to move from node to node with a new node being added to the stationary grid with each jump, but it was unclear how to incorporate the previous solution into the expanded grid. Another idea was to using a floating grid, where the nodes are fixed fractional positions between the boundaries (thus each node moves with time). The possibility of transforming the moving boundary problem into a stationary boundary problem was complicated by the need to start at the spatial origin.

Equations 1-8 were solved numerically. Given a tractable initial condition ${ }^{1}$, diffusion systems are often easily solved numerically using the Crank-Nicolson method. The moving boundary problem was handled similarly. A constant number of grid points $(N)$ were used and the distance between grid points was maintained at $(\lambda / N)$. Naturally this changes the Crank-Nicolson matrix at each step, but this poses little numerical penalty because tridiagonal matrices may be solved in $O(N)$ flops. The remaining difficulty is selecting a tractable initial condition. By assuming that the reaction front precedes a finite (but very small) distance into the core, $\lambda_{0}$, in an infinitesimally short time after starting, it may be reasoned that the diffusion proceeds much faster than the reaction front and that the concentration profile is initial slope zero, flat, and at the same level as the gas phase, except at the reaction front where the boundary conditions of Equation 8 are maintained.

The results of the exact-numerical solution are significantly different from the pseudo-steady state approximation. In brief, the approximation is invalid for small times, and the reaction front initially precedes much faster than predicted. As $\lambda$ increases, the reaction front velocity quickly reaches that of the approximation, but not before the reaction front has

\footnotetext{
1For instance, $\tau_{0}=10^{-2}$ seconds, $\lambda_{0}=10^{-6} \mathrm{~cm}$ for the above system.
} 
moved considerably further than the approximation predicts. See Figure 15 and Figure 16. The pseudo-steady state approximation predicts breakthrough at $\tau=0.3393$ while the numerical solution predicts breakthrough at $\tau=0.1713$.

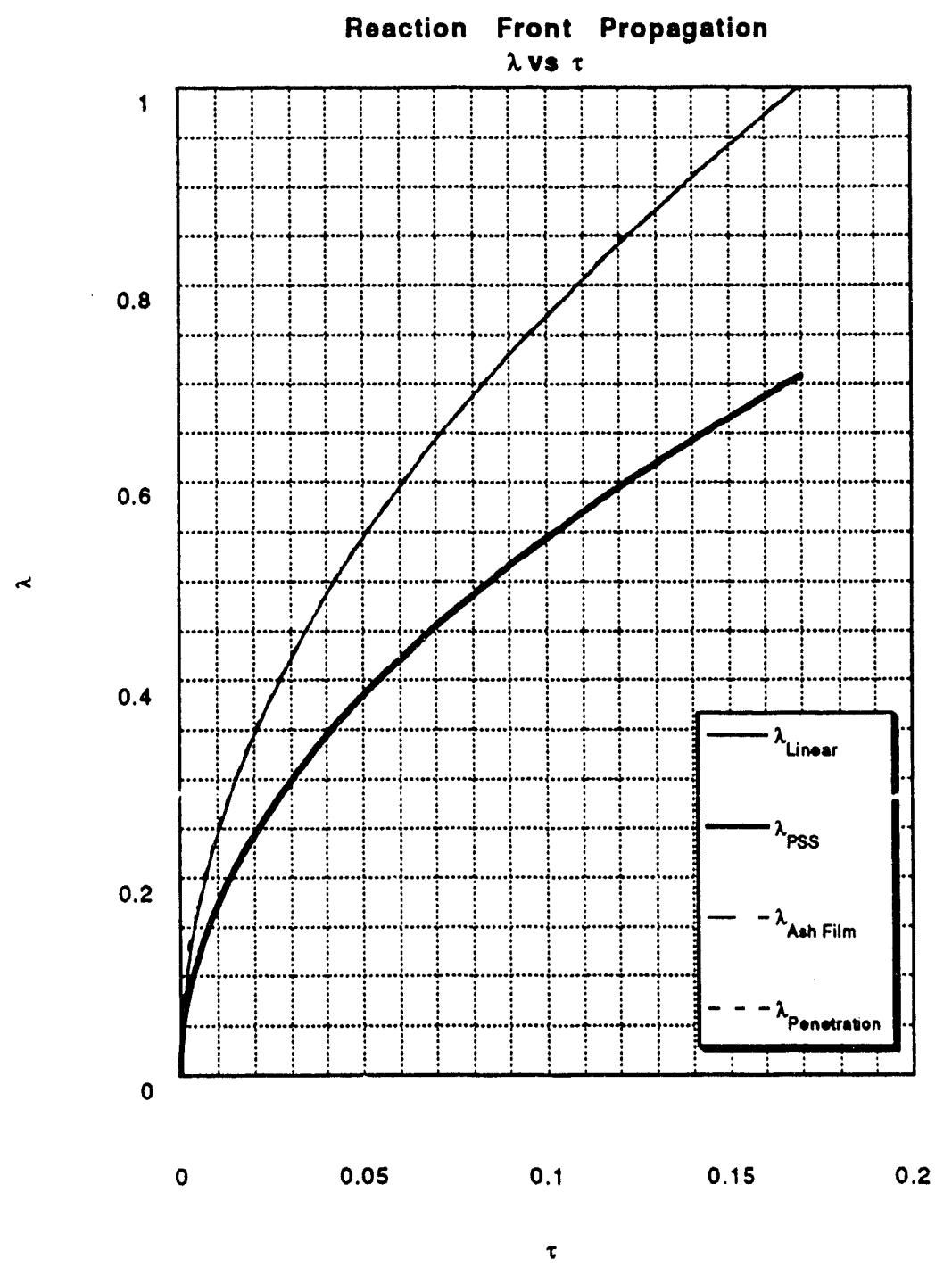

Figure 15. Results of Diffusion-limited, Infinite Gas Chamber, Homogeneous Solid Breakthrough Model. 


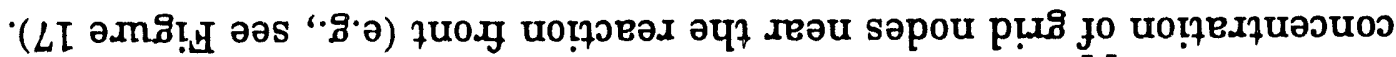

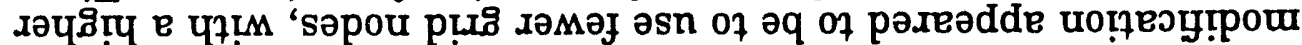

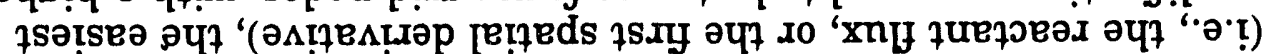

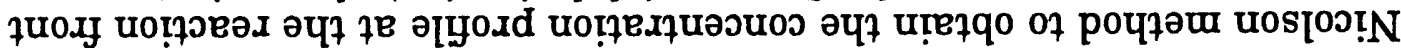

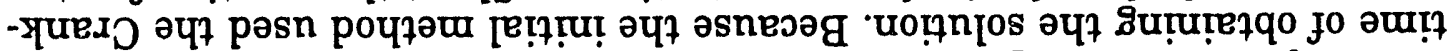

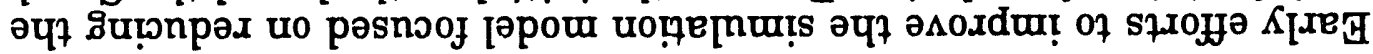

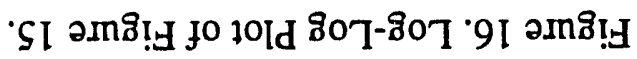

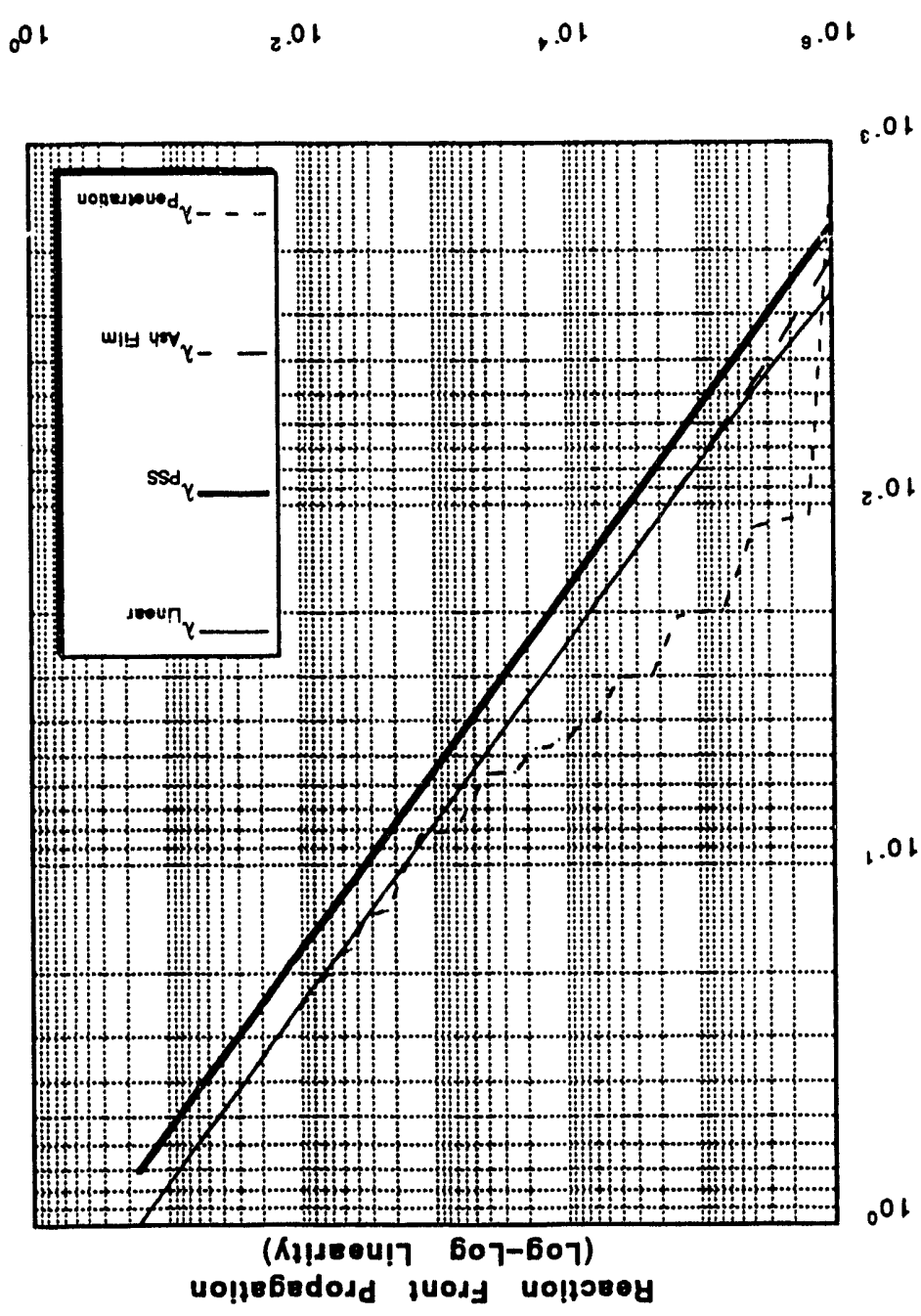




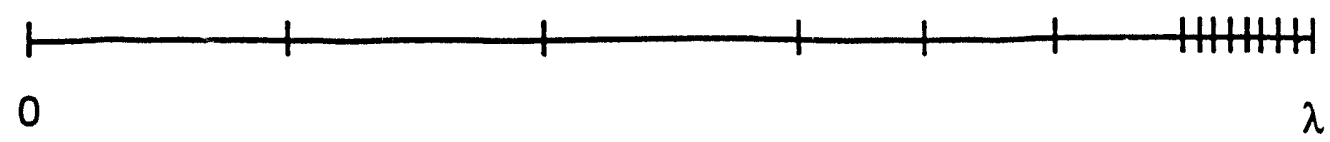

Figure 17. Uneven Grid.

The use of a uneven grid such as Figure 17 would require much less computational effort than an even and fine mesh, while still providing high accuracy where it is needed, i.e., at the reaction front, $\lambda$. However, there is a lack of documented software for uneven grid finite difference algorithms. Thus, a modified second derivative difference equation was derived from Taylor series expansions. The difficulty comes from the requirement of a very accurate first derivative. With the even grid second derivative difference equation, the first derivative is cancelled exactly, but the term remains with an uneven grid. Linear interpolation of the forward and backward first derivative difference equations and cubic splines both provide adequate accuracy. The time saved is lower than expected, due to instabilities introduced into the compritations. These result in a smaller step size than is required with an even grid. Two potential alternatives include reconstructing the model using a finite elements routine and using even grid Crank-Nicolson with the spatial domain partitioned to two regions, each with a different step size. (See Figure 18.)

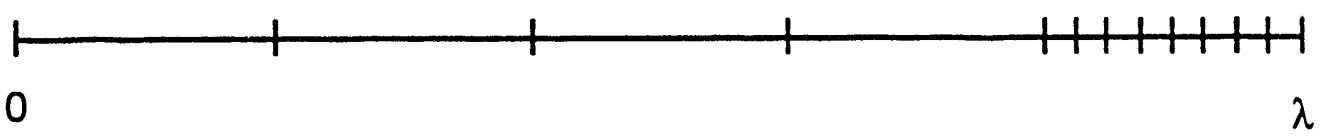

Figure 18. Bimodal Grid.

\section{PSEUdO-STEADY STATE, DIFFUSION-LIMITED, HOMOGENEOUS BREAKTHROUGH MODEL}

The easiest method of suiution is to make a pseudo-steady state approximation. This assumption results in linear concentration profiles, which makes an algebraic solution easy to determine.

$$
\begin{gathered}
\lambda=\sqrt{\alpha \tau} \\
\alpha \equiv \frac{C_{\text {shale }}}{\mathrm{C}_{\mathrm{Rxn} \text { Sites }}}\left(\mathrm{x}_{\mathrm{HCl}}^{\cdot}+2\left[\frac{\mathrm{D}_{\mathrm{H}_{2} \mathrm{O}}}{\mathrm{D}_{\mathrm{HCl}}}\right] \mathrm{x}_{\mathrm{H}_{2} \mathrm{O}}^{\cdot}\right) \\
\text { DIFFUSION-LIMITED, FINTTE GAS CHAMBER, HOMOGENEOUS SOLID } \\
\text { BREAKTHROUGH MODEL }
\end{gathered}
$$

\section{DIFFUSION-LIMITED, FINITE GAS ChAMBER, HOMOGENEOUS SOLID BREAKTHROUGH MODEL}

The diffusion-limited, infinite gas chamber, homogeneous solid breakthrough model was modified to remove the assumption that the gas chamber was infinitely large. This required the addition of mass balances on the gas chamber to account for the flow of gases through the gas chamber-oil shale interface.

The mass balances result in the following differential equations 


$$
\frac{\mathrm{d} c_{i}^{\phi}}{\mathrm{dt}}=-\frac{\mathrm{A}}{\mathrm{V}} N_{\mathrm{i}}
$$

Eqn 11.

The parameter $A / V$ is essentially the length of the reactor, assuming for convenience that the oil shale core and the reactor gas chamber have the same diameter. The ratio of the reactor length to the core length is $\gamma$. The results of the diffusion-limited, finite gas chamber, homogeneous solid breakthrough model are shown in Figures 19 and 20.

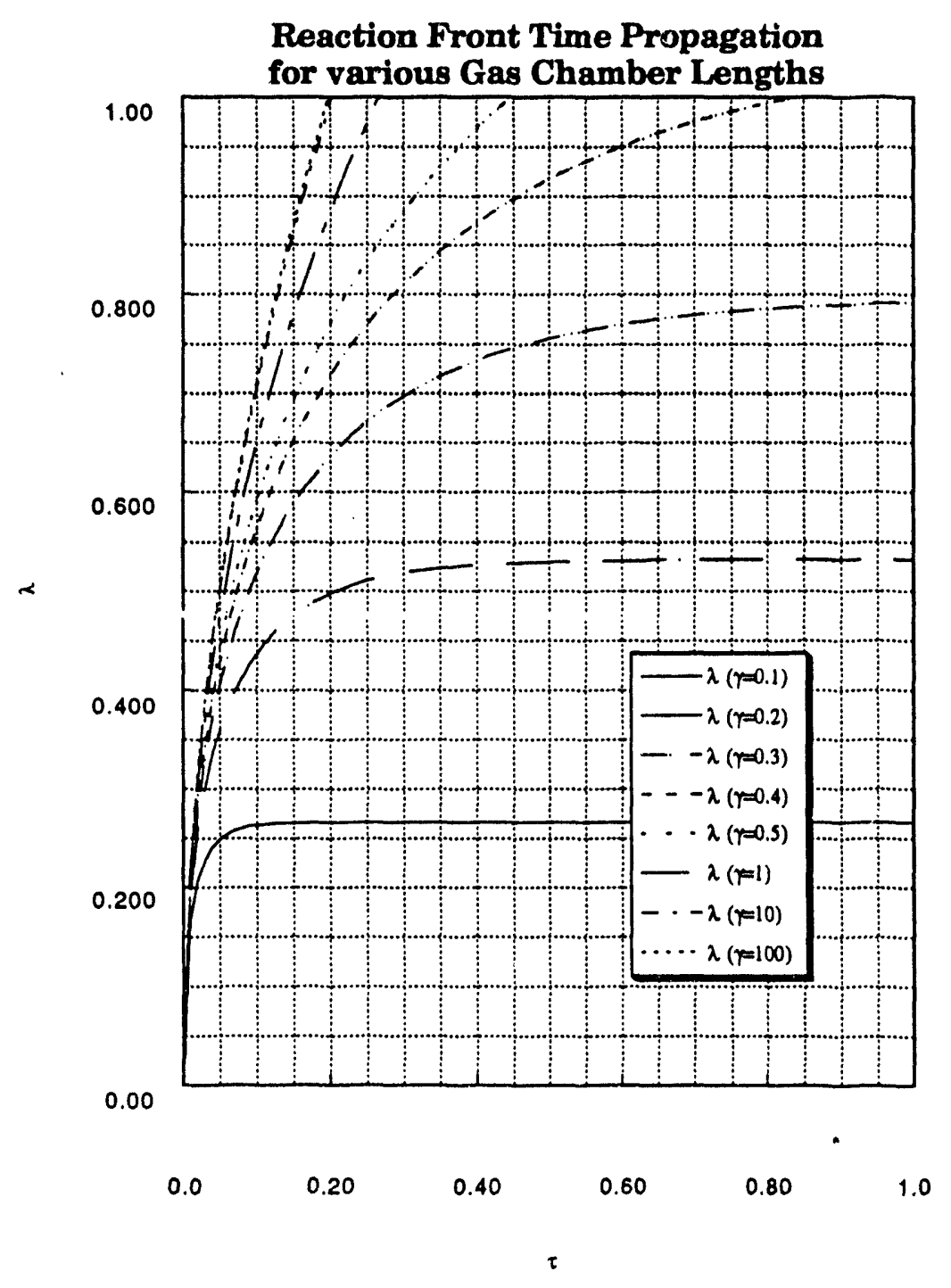

Figure 19. Results of Diffusion-limited, Finite Gas Chamber, Homogeneous Solid Breakthrough Model 
Breakthru $\tau$ as a function of $\gamma$

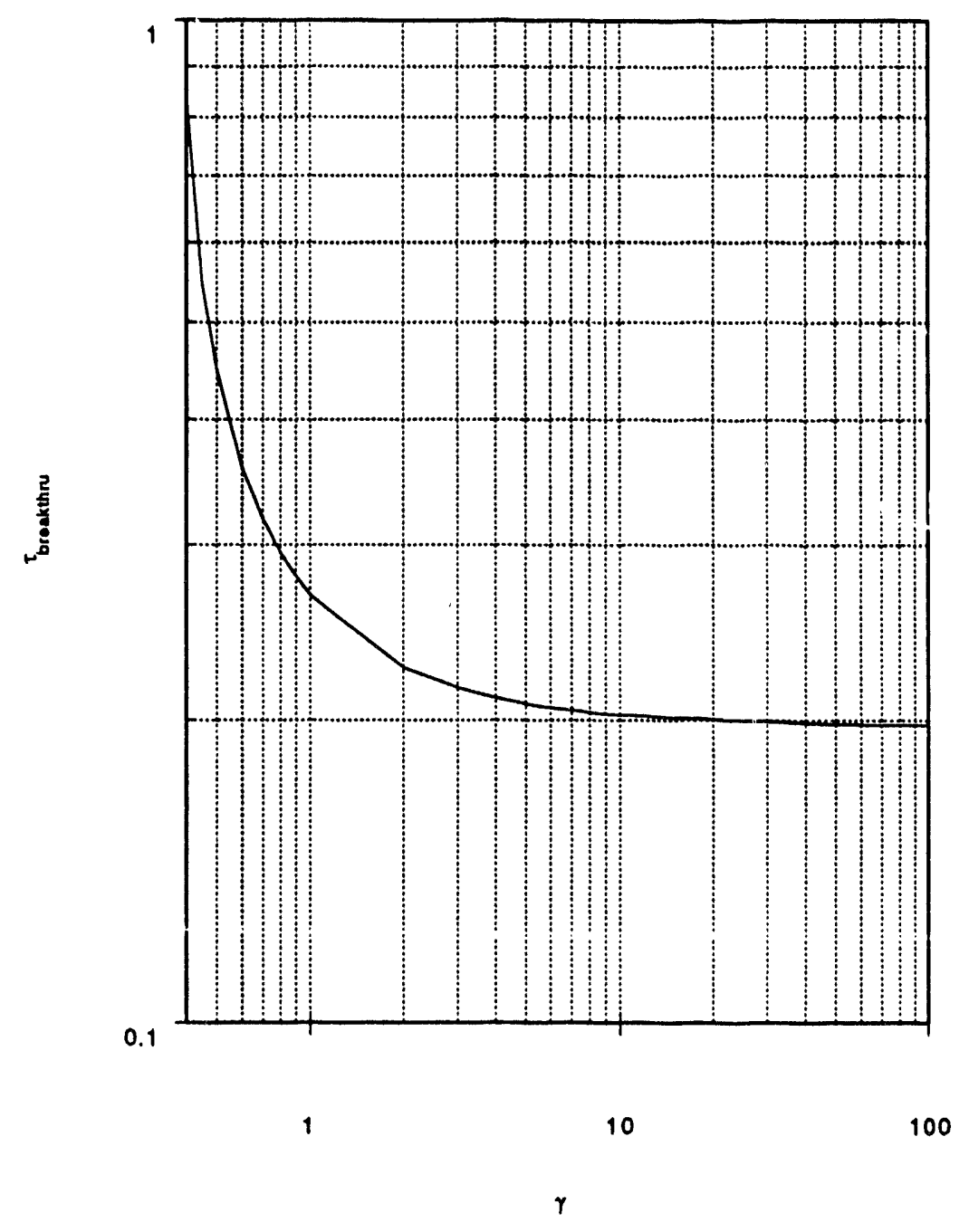

Figure 20. Breakthrough Time versus Reactor Size.

\section{PSEUdo-STEAdy STATE LAMINAE ATTACK MOdEL}

A new model has been developed. This model differs from the previous model in several aspects. Firstly, it assumes that the chemical attack proceeds primarily along laminae of high concentrations of kerogen (the laminae transport model). Secondly, it assumes that these laminae contain negligible quantities of inorganic material. After chemical attack, the freed organics transport back to the gas chamber, leaving a void. Thirdly, the chemical reactions that occur are: 


$$
\begin{array}{r}
2 \mathrm{HCl}_{(g)}+\mathrm{CaCO}_{3} \mathrm{Mg}\left(\mathrm{RCO}_{2}\right)_{(\mathrm{s})} \rightarrow \mathrm{CaMgCO}_{3} \mathrm{Cl}_{2(\mathrm{~s})}+2 \underset{\mathrm{CO}}{\mathrm{CO}_{2(g)}}+\underset{\operatorname{Rxn} 7}{2 n R^{\prime} \mathrm{H}_{(g)}} \\
\mathrm{H}_{2} \mathrm{O}_{(g)}+\mathrm{CaCO}_{3} \mathrm{Mg}\left(\mathrm{RCO}_{2}\right)_{(\mathrm{s})} \rightarrow \mathrm{CaMgCO}_{3} \mathrm{O}_{(\mathrm{s})}+2 \mathrm{CO}_{2(g)}+\underset{\operatorname{Rxn} 8}{2 n \mathrm{R}^{\prime} \mathrm{H}_{(g)}}
\end{array}
$$

where $R-$ is the bound organic kerogen and $R H$ is the freed organic molecule from the partial decomposition of $\mathrm{R}-$.

The diffusion is entirely in the gas phase. The pseudo-steady state assumption is used. Pure diffusion is assumed. The one dimensional, pure diffusion Stefan-Maxwell equations are

$$
\frac{\partial x_{i}}{\partial z}=\sum_{j=1}^{4} \frac{1}{c D_{i j}}\left(x_{i} N_{j}-x_{j} N_{i}\right)
$$

where $x_{i}$ is the $i^{\text {th }}$ component mole fraction, $D_{i, j}$ is the binary diffusion coefficient between the $i^{\text {th }}$ and $j^{\text {th }}$ components, $N_{i}$ is the molar flux of the $i^{\text {th }}$ component, $\mathrm{c}$ is the gas concentration, and $\mathrm{z}$ is the spatial variable. The boundary conditions at the reaction front $(\mathrm{z}=\zeta)$ are

$$
\begin{aligned}
& x_{1}=0 \\
& x_{2}=0 \\
& N_{3}=-N_{1}-2 N_{2} \\
& N_{4}=-\mathrm{n} N_{1}-2 \mathrm{n} N_{2}
\end{aligned}
$$

where $1=\mathrm{HCl}, 2=\mathrm{H}_{2} \mathrm{O}, 3=\mathrm{CO}_{2}$, and $4=\mathrm{R}^{\circ} \mathrm{H}$. The boundary conditions at the gas chamber $(z=0)$ are

$$
x_{i}=\frac{c_{i}^{\phi}}{\sum_{j=1}^{4} c_{j}^{\phi}}
$$

where $\phi$ indicates the component concentration in the gas chamber.

The continuity equation is

$$
\frac{\partial c_{i}}{\partial t}=\frac{\partial N_{i}}{\partial z}
$$

where $t$ is time, and $c_{i}$ is the concentration of the $i^{\text {th }}$ component. The pseudo-steady state assumption states that the time change in the system is very small compared to other variables. Thus the molar fluxes are constant with respect to distance, but may evolve over time. 
Because the fluxes are constant with respect to z, the Stefan-Maxwell equation may be expressed by

$$
\dot{\mathbf{x}}=\mathbf{A x}
$$

which may be easily integrated, giving

$$
\mathbf{x}=\operatorname{MatrixExp}\left(A \frac{z}{c}\right) \mathbf{x}_{0}
$$

where $\mathbf{x}_{0}$ is the vector of mole fractions at $z=0$. The function, MatrixExp(Z), is the exponential of the square matrix $\mathbf{Z}$, and is defined below.

$$
\operatorname{MatrixExp}(\mathbf{Z}) \equiv \sum_{k=0}^{\infty} \frac{\mathbf{Z}^{k}}{k !}
$$

There are better ways to compute the exponential of a matrix. Padé approximations are generally used by numerical computational libraries.

The matrix $\mathbf{A}$ is from the Stefan-Maxwell equations:

$$
\mathbf{A}=\left[\begin{array}{cccc}
\left(\frac{N_{2}}{D_{1,2}}+\frac{N_{3}}{D_{1,3}}+\frac{N_{4}}{D_{1,4}}\right) & \left(-\frac{N_{1}}{D_{1,2}}\right) & \left(-\frac{N_{1}}{D_{1,3}}\right) & \left(-\frac{N_{1}}{D_{1,4}}\right) \\
\left(-\frac{N_{2}}{D_{21}}\right) & \left(\frac{N_{1}}{D_{2,1}}+\frac{N_{3}}{D_{2,3}}+\frac{N_{4}}{D_{2,4}}\right) & \left(-\frac{N_{2}}{D_{2,3}}\right) & \left(-\frac{N_{2}}{D_{2,4}}\right) \\
\left(-\frac{N_{3}}{D_{3,1}}\right) & \left(-\frac{N_{3}}{D_{3,2}}\right) & \left(\frac{N_{1}}{D_{3,1}}+\frac{N_{2}}{D_{3,2}}+\frac{N_{4}}{D_{3,4}}\right) & \left(-\frac{N_{3}}{D_{3,4}}\right) \\
\left(-\frac{N_{4}}{D_{4,1}}\right) & \left(-\frac{N_{4}}{D_{4,2}}\right) & \left(-\frac{N_{4}}{D_{4,3}}\right) & \left(\frac{N_{1}}{D_{4,1}}+\frac{N_{2}}{D_{4,2}}+\frac{N_{3}}{D_{4,3}}\right)
\end{array}\right]_{\text {Eqn } 18 .}
$$

Given the boundary conditions, the equation

$$
x-\operatorname{MatrixExp}\left(A \frac{\zeta}{c}\right) x_{0}=0
$$

(where $\zeta$ is the location of the reaction front) is solved to give the actual molar fluxes.

Once the molar fluxes are known, the two equations of primary interest are integrated by one step.

$$
\begin{aligned}
& \frac{\mathrm{d} c_{i}^{\phi}}{\mathrm{dt}}=-\frac{\mathrm{A}}{\mathrm{V}} N_{\mathrm{i}} \\
& \frac{\mathrm{d} \zeta}{\mathrm{dt}}=\frac{1}{\mathrm{C}_{\mathrm{R}}}\left(N_{1}+2 N_{2}\right)
\end{aligned}
$$

with the initial conditions 


$$
\begin{aligned}
c_{i}^{\phi} & =c_{i, 0}^{\phi} \\
\zeta & =0
\end{aligned}
$$

where $A$ is the cross-sectional area of the laminae, $V$ is the volume of the gas chamber, and $c_{R}$ is the molar concentration of solid kerogen in the laminae. Integration begins at $t=0$ and continues until $\zeta=\mathrm{L}$, the length of the core. The results of the simulation are plotted in Figure 21.

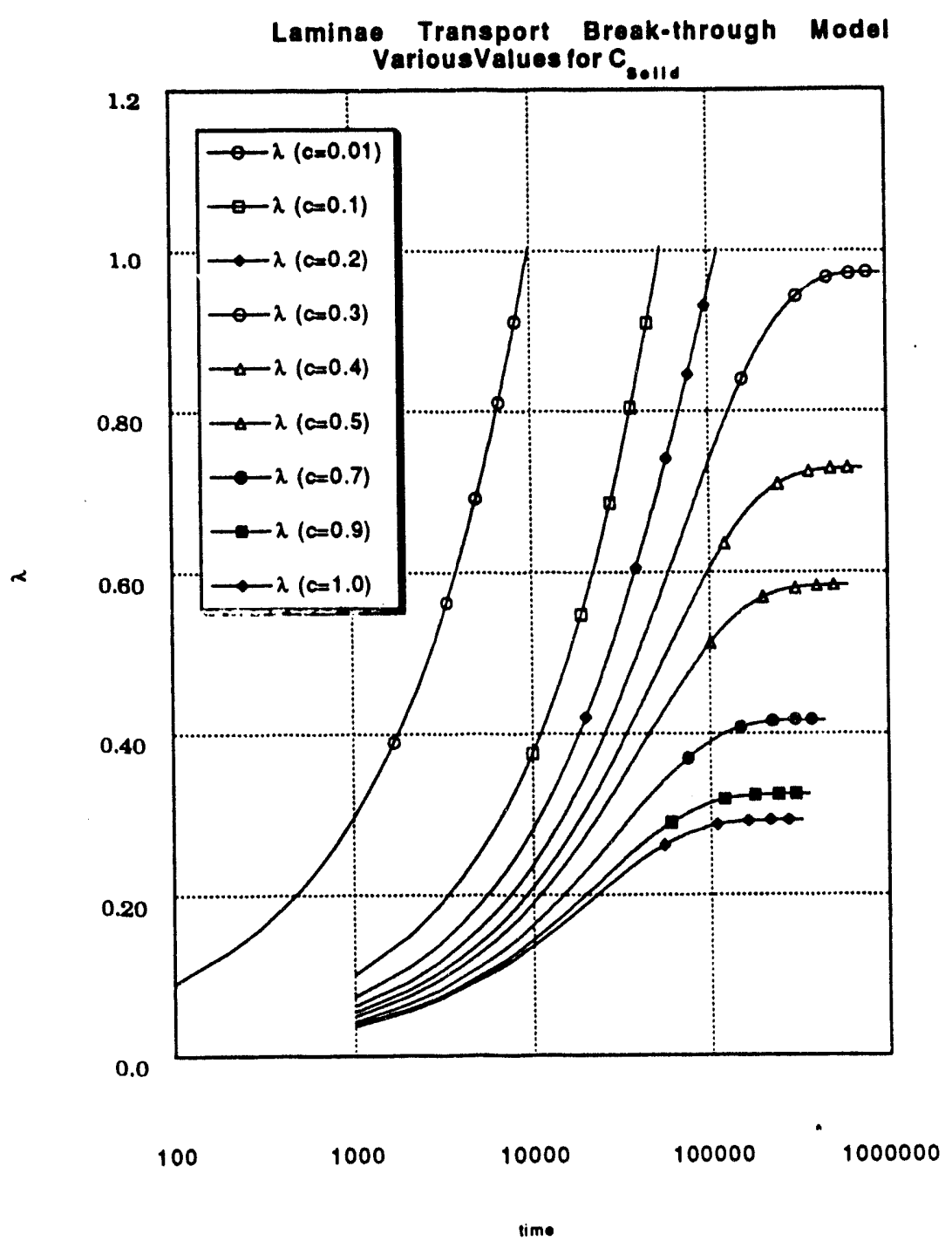

Figure 21. Results of Pseudo-Steady State Laminae Attack Model. 


\section{RATE LIMITED REACTION MODEL}

A recent literature search revealed that the pyrolysis reactions for modified in situ retorts (which are the most relevant to the chemically assisted in situ recovery method) are rate limited, instead of mass transport limited. Because the models previously developed by the researchers assumed that the reactions would be mass transport limited, it is necessary to modify the models.

The homogeneous breakthrough model previously derived and presented assumed that the reactions were diffusion limited. For finite differencing purposes, the one-dimensional diffusion problem is put onto a grid. The spatial variable is $\mathrm{z}$, and the node index $\mathrm{j}$ runs from 0 to $\mathrm{m}+1$.

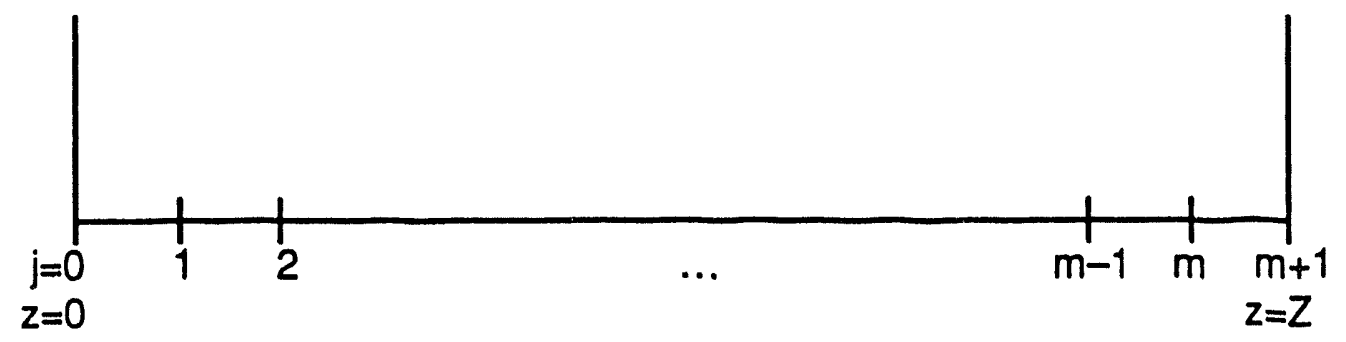

Figure 22. Node Point Labelling.

The Stefan-Maxwell equation for ordinary diffusion of ideal gases is

$$
\nabla x_{i}=\sum_{h=1}^{n c} \frac{1}{c D_{i, h}}\left(x_{i} N_{h}-x_{h} N_{i}\right)
$$

where $x_{i}$ is the mols fraction of component $i, N_{i}$ is the molar flux of component $i, c$ is the molar concentration of the gas mixture, $D_{i, h}$ is the binary diffusivity of component $i$ through component $h$, and $n c$ is the number of components.

By discretizing the variables on to the grid (see Figure 22), using the second order central difference formula for the first derivative, and assuming that the total molar concentration and the total molar flux of the gas mixture are both constant with respect to $z$, the Stefan-Maxwell equation becomes:

$$
\frac{\mathbf{x}_{i, j+1}^{(\mathbf{k})}-\mathbf{x}_{i, j-1}^{(\mathbf{k})}}{2 \Delta \mathbf{z}^{(\mathbf{k})}}=\sum_{h=1}^{n c} \frac{1}{c^{(\mathbf{k})} D_{i, h}}\left(x_{i, j}^{(\mathbf{k})} N_{h, j}^{(\mathbf{k})}-\mathbf{x}_{\mathrm{h}, \mathrm{j}}^{(\mathbf{k})} N_{\mathrm{i}, \mathrm{j}}^{(\mathbf{k})}\right) \text { for } \mathrm{j} \in[1, \ldots, \mathrm{m}]
$$

where $x_{i, j}$ is the mole fraction of component $i$ at node $j$ (the superscript " $(\mathbf{k})^{n}$ indicates during time step $k$ ), $N_{i, j}$ is the molar flux of component $i$ at node $j$. Equation 24 is subject to two constraints: 


$$
\begin{aligned}
& \sum_{h=1}^{n c} x_{h, j}^{(k)}=1 \\
& \sum_{h=1}^{n c} N_{h, j}^{(k)}=N_{t}^{(k)}
\end{aligned}
$$

Eqn 26.

The continuity equation in one dimension ( $\mathrm{z}$ ) without any homogeneous reaction is:

$$
\frac{\partial c_{i}}{\partial t}=-\frac{\partial N_{i}}{\partial z}
$$

where $c_{i}$ is the molar concentration of component $i$ and $t$ is the temporal variable. By discretizing the continuity equation and using the implicit Euler equation, Equation 27 becomes:

$$
x_{i, j}^{(k)}=x_{i, j}^{(k-1)}+\frac{\Delta t}{2 c \Delta z}\left(N_{i, j+1}^{(k)}-N_{i, j-1}^{(k)}\right) \text { for } j \in[1, \ldots, m]
$$

Eqn 28.

Equations 24-28 apply to the nodes where diffusion occurs. At the outside nodes $(j=0$ and $j=m+1)$ special conditions apply. At $j=0$, the mole fractions are identical to the mole fractions of the gas mixture in the gas chamber, $\mathrm{yi}_{\mathrm{i}}$.

$$
x_{i, 0}^{(\mathbf{k})}=y_{i}^{(\mathbf{k})}
$$

subject to the cons, traint of Equation 25. Equation 26 is modified

$$
\frac{\mathbf{x}_{i, 1}^{(\mathbf{k})}-\mathbf{x}_{\mathrm{i}, 0}^{(\mathbf{k})}}{\Delta \mathbf{z}^{(\mathbf{k})}}=\sum_{\mathrm{h}=1}^{\mathrm{nc}} \frac{1}{c^{(\mathbf{k})} D_{i, \mathrm{~h}}}\left(\mathrm{x}_{\mathrm{i}, 0}^{(\mathbf{k})} \mathrm{N}_{\mathrm{h}, 0}^{(\mathbf{k})}-\mathrm{x}_{\mathrm{h}, 0}^{(\mathbf{k})} \mathrm{N}_{\mathrm{i}, 0}^{(\mathbf{k})}\right)
$$

Eqn 30

subject to the constraint of Equation 26. The continuity equation is irrelevant here.

At the node $j=m+1$, the conditions are determined by the heterogeneous reaction kinetics. For simplicity, it is assumed that the reaction kinetics are first order with respect to the gaseous molar concentration of $\mathrm{HCl}$ at that node. Thus the molar fluxes at the node $j=m+1$ are

$$
\mathrm{N}_{\mathrm{i}, \mathrm{m}+1}^{(\mathbf{k})}=-v_{\mathrm{i}} \mathbf{k c ~ x}_{\mathrm{i}=\mathrm{HCl}, \mathrm{m}+1}^{(\mathbf{k})}
$$

where $\mathbf{k}$ is the rate constant and $v_{i}$ are the stoichiometric constants. The total molar flux is computed from Equation 31 by summing the molar fluxes 


$$
N_{t}^{(k)}=\sum_{h=1}^{n c} N_{h, m+1}^{(k)}=-k c x_{i=H C l, m+1}^{(k)} \sum_{h=1}^{n c} v_{h}
$$

Equation 24 is again modified

$$
\frac{x_{i, m+1}^{(k)}-x_{i, m}^{(k)}}{\Delta z^{(k)}}=\sum_{h=1}^{n c} \frac{1}{c(k) D_{i, h}}\left(x_{i, m+1}^{(k)} N_{h, m+1}^{(k)}-x_{h, m+1}^{(k)} N_{i, m+1}^{(k)}\right)
$$

subject to Equation 26.

When Equations 24 and 28 are used only for

$$
\mathrm{i} \in[1, \ldots, \mathrm{nc}-1]
$$

and Equations 25 and 26 are incorporated, then the system of non-linear equations (Equations 24-26, 28-33) is well determined and solvable, provided values for $\Delta \mathrm{z}, \mathrm{c}, \mathrm{y}_{\mathrm{i}}, \mathrm{D}_{\mathrm{i}, \mathrm{h}}$ and $\mathrm{k}$ are known $a$ priori. A program to solve this system of non-linear equations was written in FORTRAN on an IBM RS/6000 using the NAG non-linear system of equations solver routine. Completing the model in a fashion similar to that used for the PseudoSteady State Laminae Attack Model would be straight forward.

\section{STOCHASTIC FISSURE MODEL}

Comparison of the breakthrough times in the various experiments (see Table 1) reveals that the breakthrough times do not follow any trend. Breakthrough time is independent of the temperature, and is independent of the average partial pressure of $\mathrm{HCl}$ in the gas chamber. In fact the breakthrough times appear to be random.

The randomness of the breakthrough times and the knowledge of the laminar structure of oil shale suggest that the penetration of the reactive gases through the oil shale core is not straight forward (so to speak). The laminar structure makes the bulk oil shale brittle, especially along the interface between laminae. Thermal expansion, mineral decomposition, and even rough handling undoubted result in a large number of fissures at these interfaces. However, the number, size, and location of the fissures is not deterministic, but instead is stochastic.

The presence of fissures through the core must have a significant effect on the breakthrough time. There are at least three simple cases. See Figure 23. 

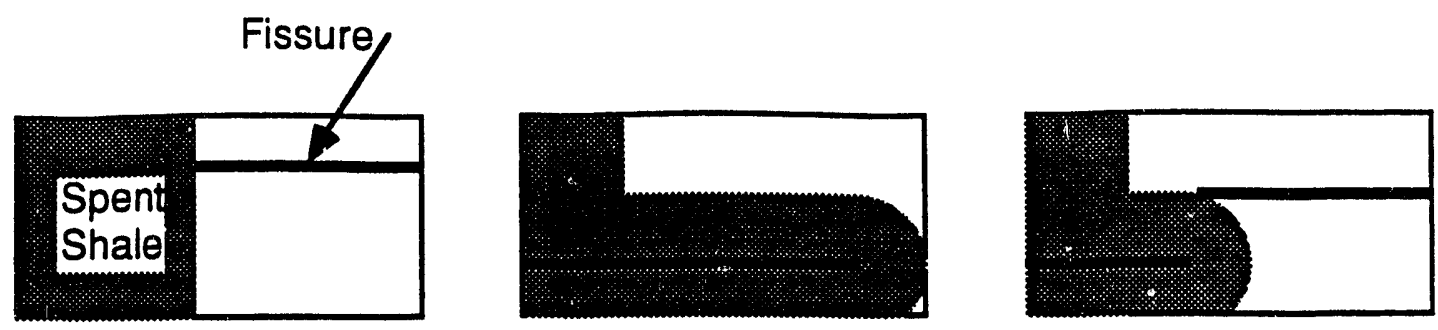

Figure 23. Examples of Fissure Enhanced Breakthrough.

The first case is where there are one or more fissures open to the back face (right side), but none are open to the front face (left side). Penetration progresses normally from the front face, until the reaction front encounters a fissure. At this point, breakthrough occurs even though most of the core is unreacted.

The second case is where one or more fissures are open to the front face, but none are open to the rear face. Penetration starts from every available surface and progresses equally from all points. Breakthrough occurs normally, but sooner than expected because the reaction front started much nearer to the rear face than would be otherwise expected. Note that considerably more core is reacted than in the first case.

The third case is a simple combination of the first and second cases. Fissures are open to both the front and back faces, but no fissure penetrates all the way through the core. The reaction front begins along all available surfaces as in the second case. Breakthrough occurs as in the first case: when the reaction front encounters a fissure open to the rear face.

Thus the rate of penetration through the oil shale core is enhanced by fissures that are formed by stochastic processes. Breakthrough times can not be predicted without information about the following distributions; number of fissures, fissure sizes, and fissure locations. If it is assumed that the gas concentrations are constant along the lengths of the fissures, then the breakthrough time is indicative of the distance that the reaction front was required to travel to obtain breakthrough.

One particular consequence of the Stochastic Fissure Model is that breakthrough bears little relation to the amount of unreacted kerogen remaining in the core. The initial arrangement of the fissures determines the amount of the core that is initially isolated. If little of the core is isolated, then the recovery will be quicker than when the core is largely isolated. This is because the rate of recovery of oil depends on the surface area available for chemical attack. Few fissures means the available area is smaller, which implies that the total rate of reaction is smaller. 


\section{CONCLUSION}

The research project uncovered a number of interesting facts and provided a large number of engineering details necessary for further research.

Oil shale does decompose at relatively low temperatures in the presence of $\mathrm{HCl}, \mathrm{H}_{2} \mathrm{O}$, and $\mathrm{CO}_{2}$. Furthermore, the decomposition reactions penetrate into solid pieces of oil shale in very little time. The bulk penetration rate is stochastic, and successful modelling will require this be accounted for. Significant recovery can be achieved, even with large pieces of oil shale.

We discovered how to perform chemically assisted penetration experiments on oil shale. The key points are corrosion resistance, instrument protection, and thermal stability. All exposed materials must be corrosion resistant. Extremely high temperature epoxies must be used to glue the oil shale to the pipe. All materials of construction must be extremely resistant metals. Ordinary stainless steel will not suffice, except where very thick walls may be used. The best material is C-276. Effort must be taken to protect all sections of the experiment, especially distant sections. For instance, inert gas sweeping of the tubing leading to the pressure transducers is highly desirable. The PTs themselves must not be exposed to the reactive gas mixture; even PTs made of stainless steel will fail. A diaphragm PT isslation unit must be used to protect the PTs.

We confirmed through a limited number of experiments that significant quantities of organic material may be recovered with the chemically assisted in situ retort procedure. We discovered through a few experiments that significant penetration into solid cores may be obtained through chemical reaction. The permeability of the penetrated core is much larger than that of the raw oil shale, though no quantitative measurements were made. Porosity measurements were not made.

We discovered that chemical flooding is superior to chemical soaking. Simply soaking the oil shale in the reactive gas mixture is not enough. Gas flow is necessary to remove the freed oil, and to expose all sections of the oil shale to the reactive gas mixture. Furthermore, breakthrough maybe expected prior to complete recovery of the shale oil. Thus chemical flooding is necessary to achieve acceptable process efficiency.

We developed several models to simulate the breakthrough process. The last models, the Rate Limited Reaction Model and the Stochastic Fissure Model have not yet been completed. 


\section{REFERENCES}

1 George H. Vandegrift, Randall E. Winans, Robert G. Scott, and E. Philip Horwitz. Quantitative Study of the Carboxylic Acids in Green River Oil Shale Bitumen. Fuel, 59(9), pp 627-633.

2 Richard D. Blakeley. A Chemically-Assisted Retorting Method. Masters of Science Thesis, University of Colorado-Boulder, Department of Chemical Engineering. (c) 1985.

3 Julian Szekely, James W. Evans, and Hong Yong Soın. Gas-Solid Reactions. Academic Press, Inc. ㅇ 1976.

4 J. J. Schmidt-Collérus and C. H. Prien. Investigations of the Hydrocarbon Structure of Kerogen from Oil Shale of the Green River Formation. Science and Technology of Oil Shale. T. F. Yen, Editor. (C) 1976.

5 T. F. Yen. Structural Investigations on Green River Oil Shale Kerogen. Science and Technology of Oil Shale. T. F. Yen, Editor. (C) 1976.

6 D. K. Young, S. Shih, and T. F. Yen. Mild Oxidation of Bioleached Oil Shale. Science and Technology of Oil Shale. T. F. Yen, Editor. (C) 1976.

7 John H. Campbell, George H. Koskinas, and Normal D. Stout. Kinetics of Oil Generation from Colorado Oil Shale. Fuel, 57(6), pp 372-376 (1978).

8 Alan C. Stanton and Joel A. Silver. Measurements in the $\mathrm{HCl} 3 \leftarrow 0$ Band Using a Near-IR InGaAsP Diode Laser. Applied Optics, 27(24), 5009 (1988).

9 Motoichi Ohtsu, Hiroki Kotani, and Haruo Tagawa. Spectral Measurements of $\mathrm{NH} 3$ and $\mathrm{H} 2 \mathrm{O}$ for Pollutant Gas Monitoring by 1.5 um InGaAsP/InP Lasers. Jpn. J. Appl. Phys. 22, 1553 (1983). 

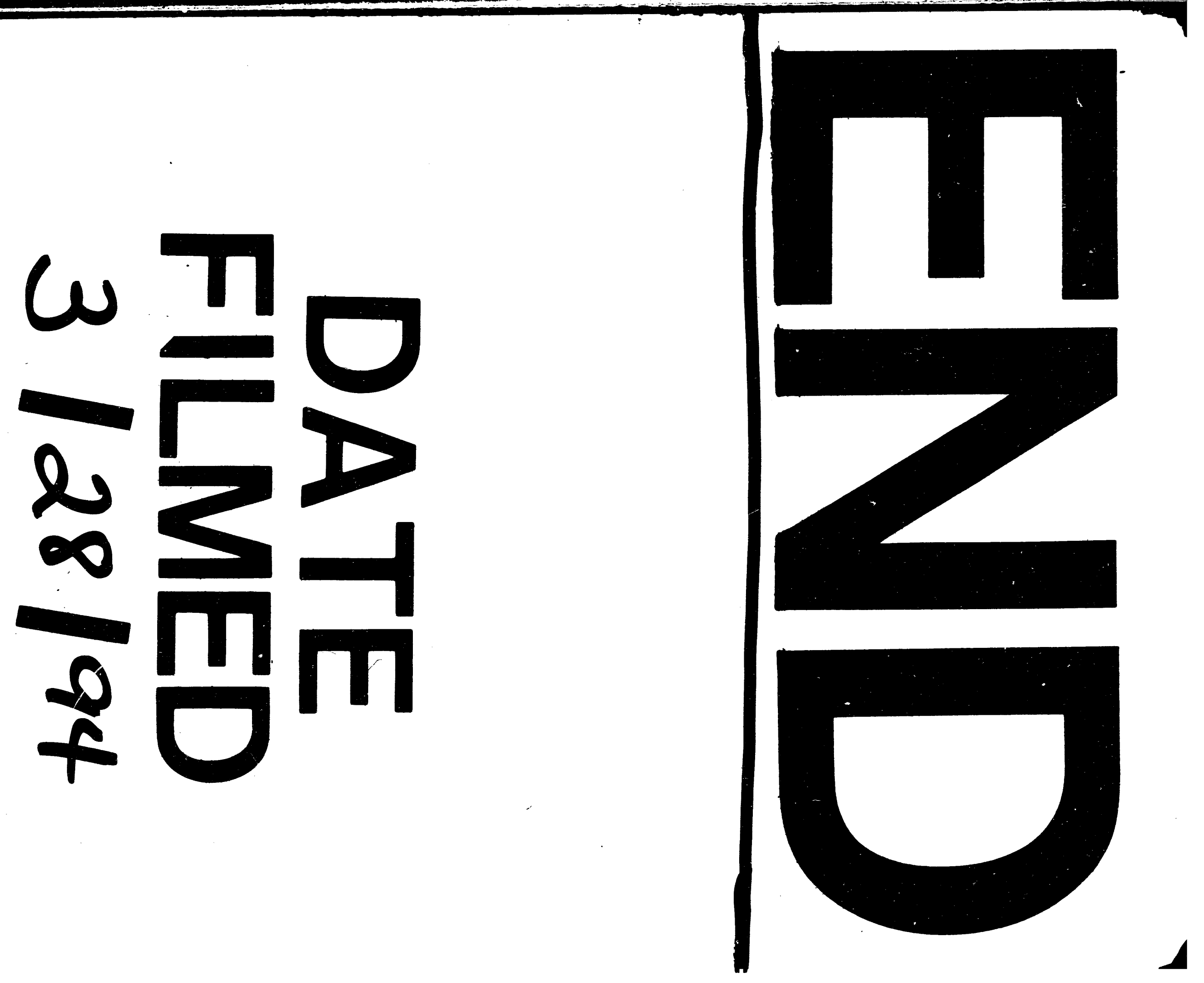
